Bull. Fac. Agric., Cairo Univ., 70:205 - 217 (2019)

\title{
THE ROLE OF AGRICULTURAL EXHIBITIONS FOR MEETING FARMERS' REQUIREMENTS AND THEIR MOTIVES FOR PRESENCE "A CASE STUDY" ON THE SECOND INTERNATIONAL AGRICULTURAL ALEXANDRIAN EXHIBITION, AGRO- ALEX, BORG EL ARAB, ALEXANDRIA
}

\author{
(Received:14.7.2019)
}

\author{
By \\ Ola M. S. El - Kashef, Safaa A. F. Al - Bendari * and Hanan N. A. Tahawi* \\ Department of Agricultural Extension Education, Faculty of Agriculture \\ (El-Shatby), Alexandria University, Egypt \\ * Agricultural Extension and Rural Development Research Institute , \\ Agricultural Research Center, Alexandria, Egypt
}

\begin{abstract}
The purpose of the present research was to identify the main motives of the farmers to attend the Second International Agricultural Alexandrian Exhibition, Agro-Alex, and the actual role of this exhibition for meeting visitor/farmers motivations in order to supply them with the latest modern agricultural technologies for the Alexandrian $2^{\text {nd }}$ International Agricultural Exhibition in Borg ElArab, Alexandria, in addition to farmers' suggestions to develop the benefit concerning this agricultural exhibition in the next years. A questionnaire form with individual interviews was used to collect data from a purposive sample of 140 farmers from the exhibition visitors, who were interviewed during the period of the second Agro-Alex exhibition in November, 2018. Data were analyzed using percentages, frequencies, mean, and standard deviation; additionally the qualitative analysis method was used. The main results included the following: 1- The majority of the respondents $(82.1 \%)$ stated that activities and services offered by the exhibition were medium and high. 2- The reason / motives for the participants to attend Alexandrian International Agricultural Exhibition were 14 reasons, as $78.5 \%$ of the respondents cited attendance for more than five reasons. 3- The results also showed that the majority of the respondents $(92.8 \%)$ achieved their actual needs with a medium and high degree. 4- Most of respondents (85\%) indicated that "collecting information on agricultural products or services offered" topped the first order in achieving their motives, which were considered the most motivated for them. 5- That 87 of the respondents $(60 \%)$ mentioned a set of suggestions (16 suggestions) that could increase the effectiveness of the studied exhibition as an extension, educational and communicational method for improving their knowledge regarding the different agricultural field; such as field of animal and poultry production, presenting new species of improved breeds for export and fish production and requirements of fishery farms, respectively.
\end{abstract}

Key words: Agro-Alex exhibition - motives - meeting needs - exhibition visitors. 


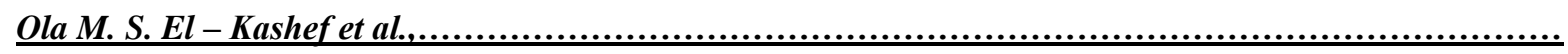

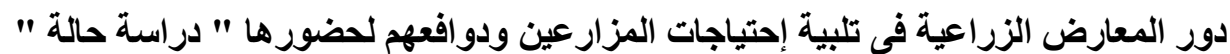

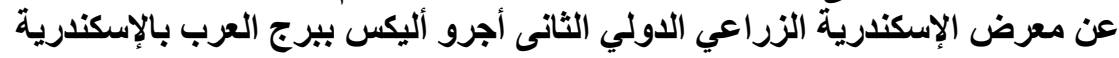
علا ممدوح صلاح الكاشف ـ صفاء أحمد فهيم البندارى* ـ حنان نجيب على طحاوى*

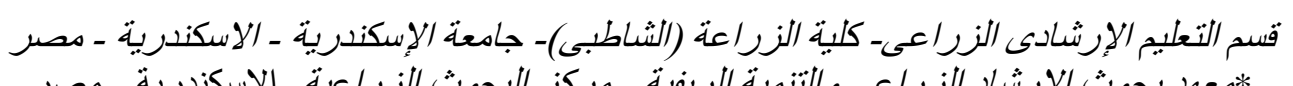

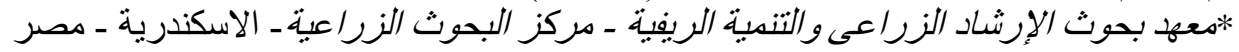

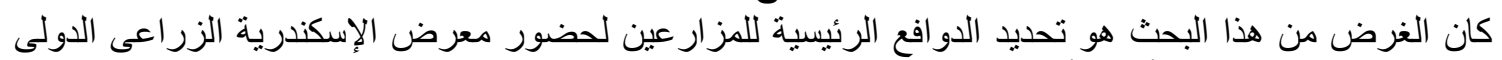

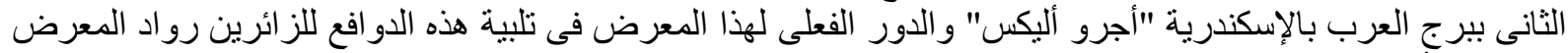

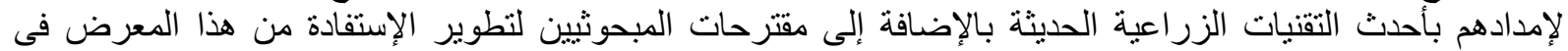

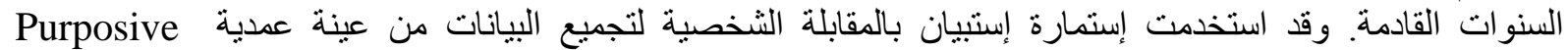

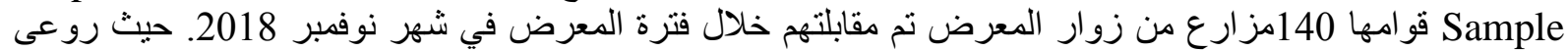

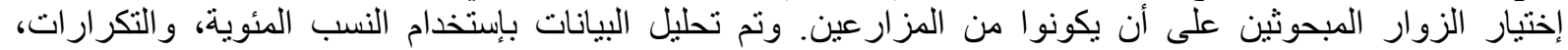

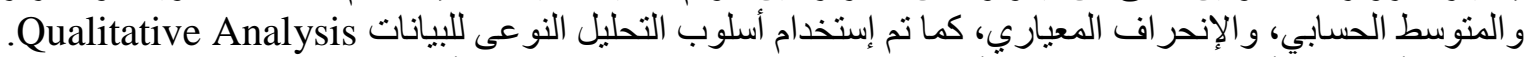

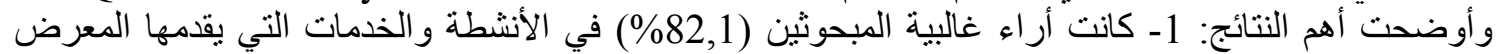

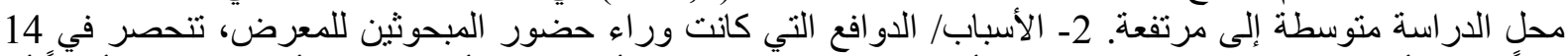

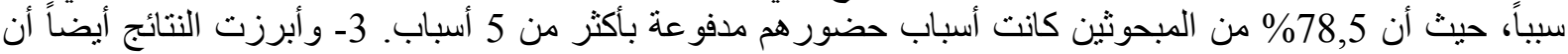

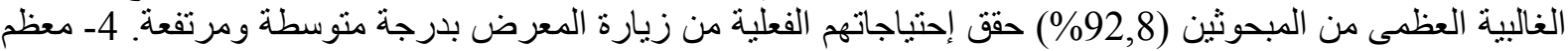

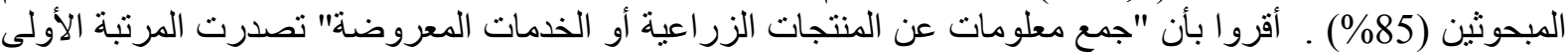

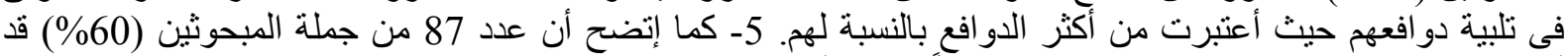

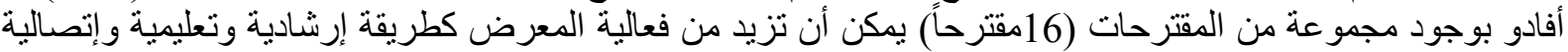

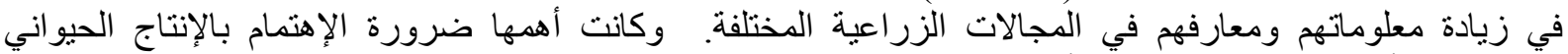

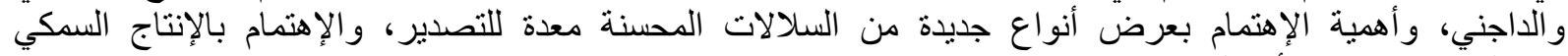
ومستلزمات مز ارع و الأسماك.

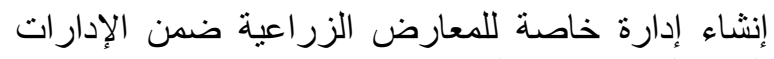
التابعة لها ( مديرية الزر اعة بالإسكندرية، لإعارية 2018).

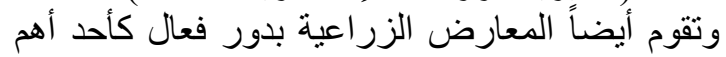

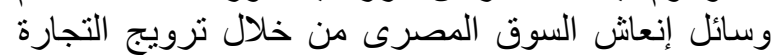

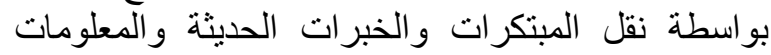

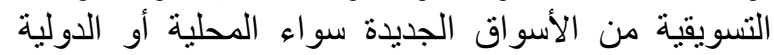

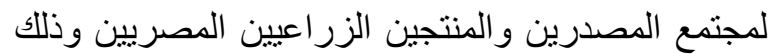

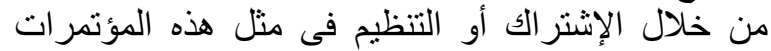

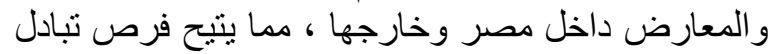

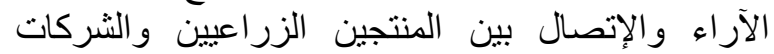

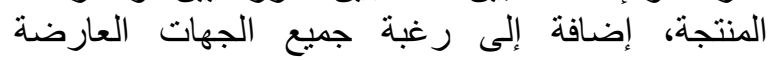
والثركات لفتح منافذ تسويقية جديدة محلية الإلية وخارجية

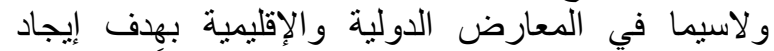

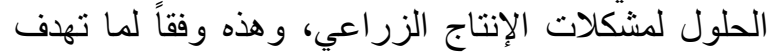

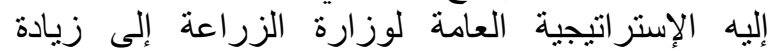
الصادرات من المنتجات الزراعية (الديب وأخرونة الزية

وبإستعر اض ماأنيح من دراسات وبحوث فى هذا

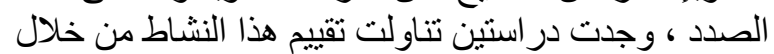

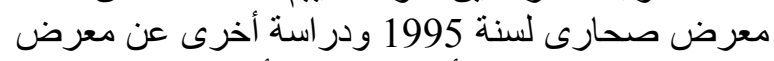
صحارى لعام 2001، وأبرزت النتائج أن غالبية المبحوثين

\begin{abstract}
1.المشكلة البحثية

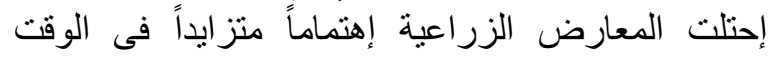

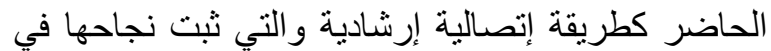

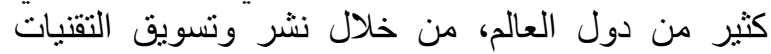

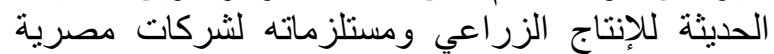

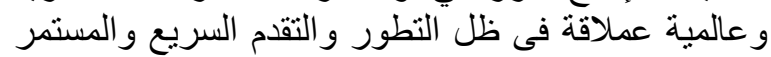

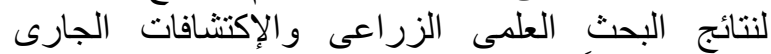

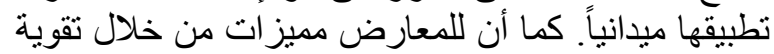

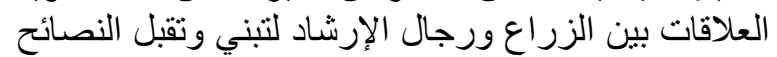

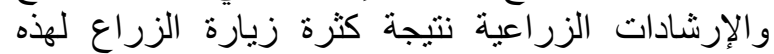

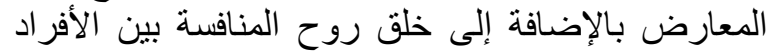

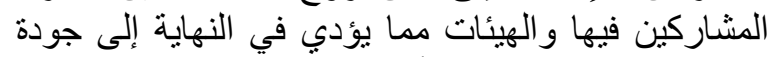

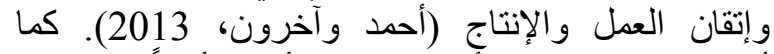

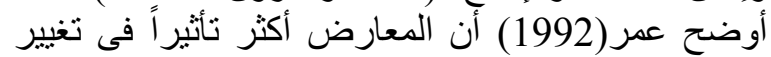

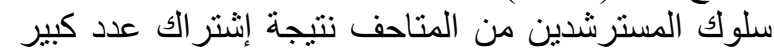

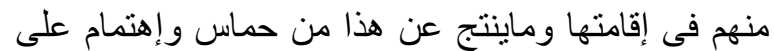

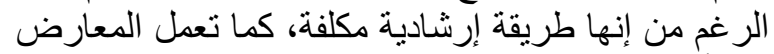

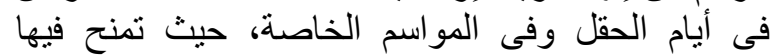
الجوائز التشجيعية للفائزين ويقام بها بعض التئل التجارب

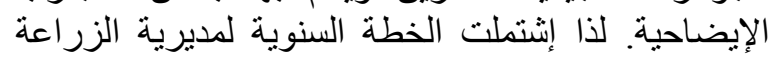

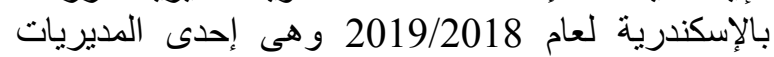
التابعة لوزارة الزراعة وإستصلاح الأراضى بمصر على المديري
\end{abstract}


التى تناولت دور المعارض الزراعية خاصة بعد تنظيم

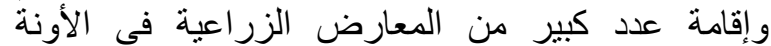

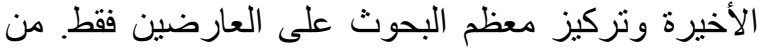

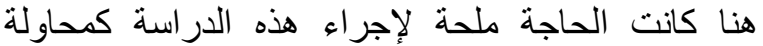

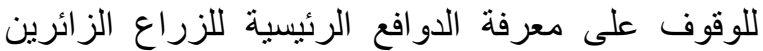

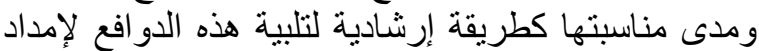

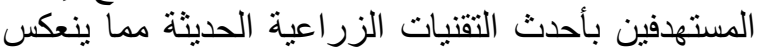

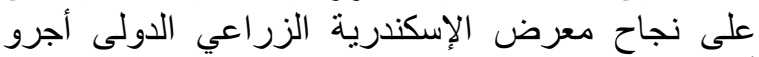
أليكس فى السنو ات القادمة.

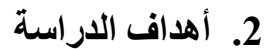

يستهدف هذا البحث بصفة أساسية الوقوف على الزئ الزئي

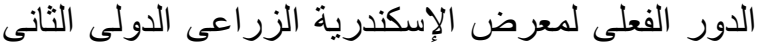

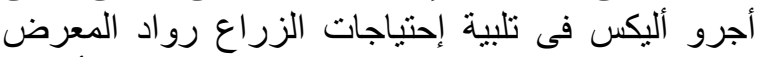
ببرج العرب بالإسكندرية، وذللك من خلال تحقية الزيق الأهداف الفر عية التالية: - الية

1) التعرف على بعضية النعض الخصائص المميزة للزراع المبحوثيين رو اد المعرض.

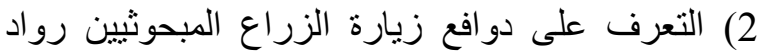
المعرض لمعرض الإسكندرية الزراعى الزع الدولى الميكى الثانى

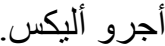

3) تحديد دور معرض الإسكندرية الزر اعى الدولى الثانى أجرو أليكس فى تلبية إحتباجات المبحوثينين الزراعين.

4) مقترحات المبحوثين الزائرين لمعرض إلئين إسكندرية

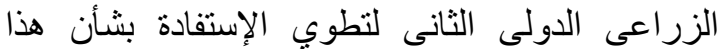
المعرض الزراعى فى العام القادي.

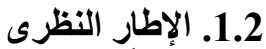

نظر اً لأن الهرف الرئيسى لهذا البحث تحديد الدوافع

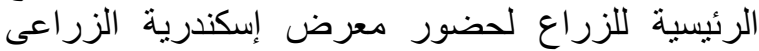

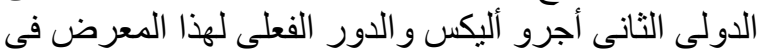

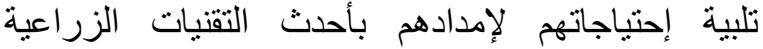
الحديثة، فإن الإطار النظرى الذّى تم الإستعانة بها، إنتمل

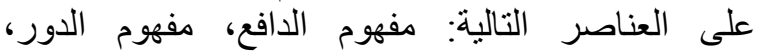
المؤشر ات المحددة لقياس فعالية المعارض الإرشادية.

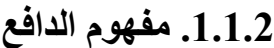
الدافع هو حالة داخلية في الكائن الحي نستثير سلوكه

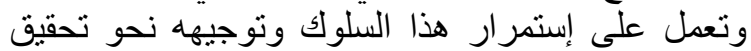

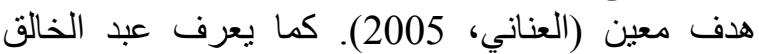
(2006) الدافع على أنه حالة من الإثارة أو التنبيه داخل التيل

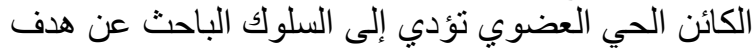

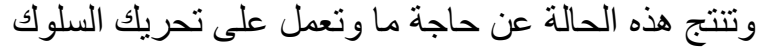
وتنشيطه وتوجيهه. وقد إستندت الدراسة إلى مفهوم الدافع

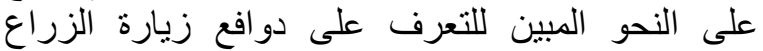

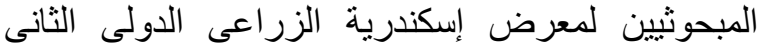
أجرو أليكس محل الدر اسة.

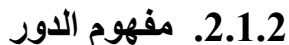

يعرف (Merton,1957) الدور بأنه مجموعة من من الاور

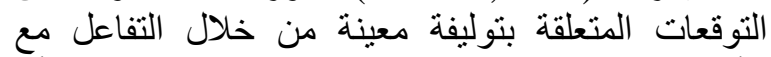

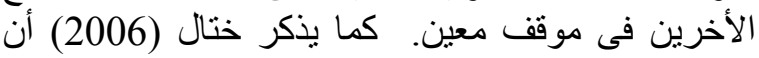
الدور يتضمن نسق من التوقعات التى نوجد فى البيئة
إسنطاعو ا تحقيق دو افعهم/ هدفهم من زيارة المعرض، كما إليا

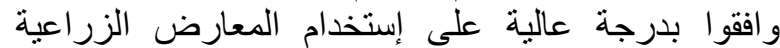

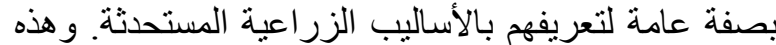

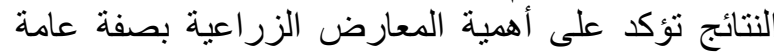

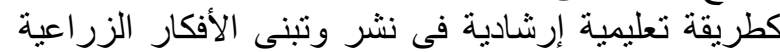

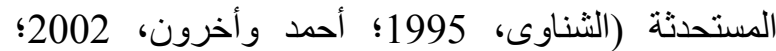
الديب و أخرون، 2014). وفى نفس الصدد تم إجراء هذه دونه

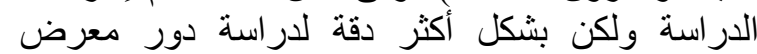

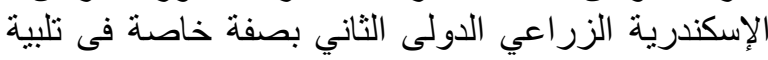

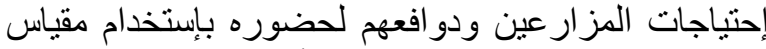

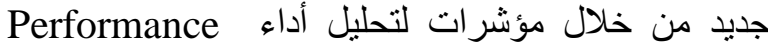
Analysis يضم مجمو عة من السمات وفى هذا السياق كان إهتمام وزارة الزراعة التهات بتطوير

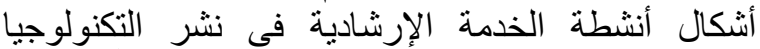

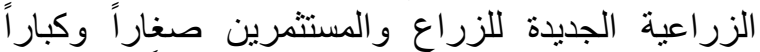

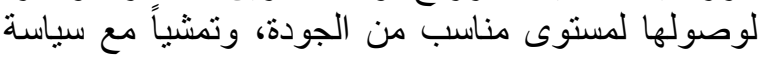

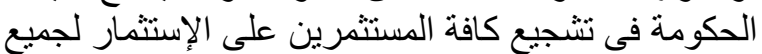

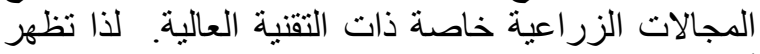

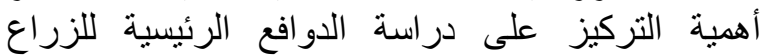

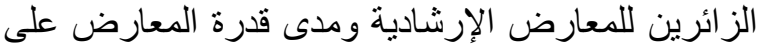

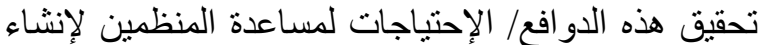

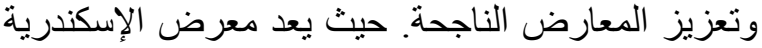
الزراعي الدولي أجرو أليكس في دورنه النئ الثانية من أكبر المعارض الزر أعية. - الزي

بهدف معرض الإسكندرية الزراعي الثناني ( أجرو

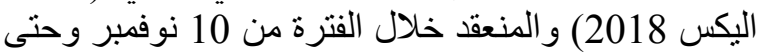
12 نوفمبر بمشاركة خمسون شركة، يهدف إلى الى النهوض

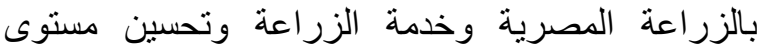

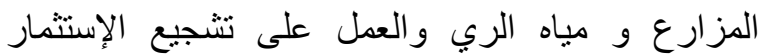

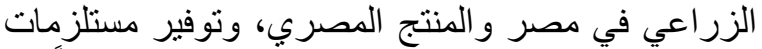

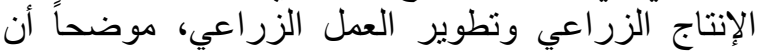

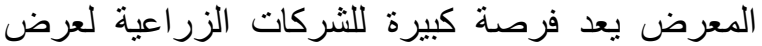

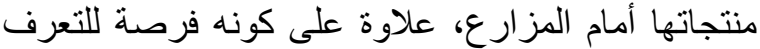

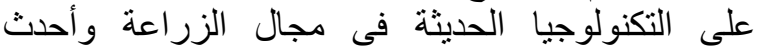

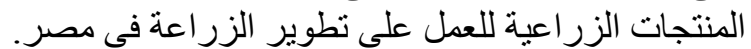

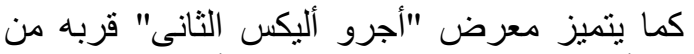

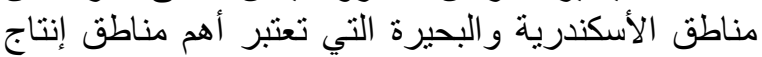

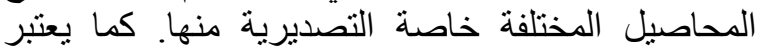

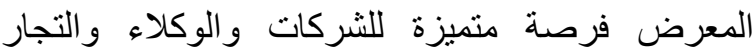

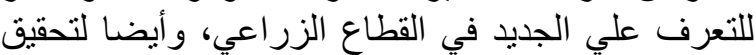

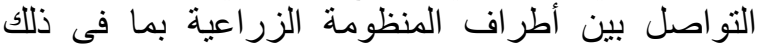

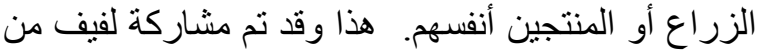

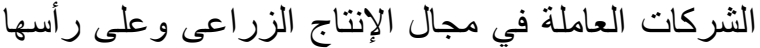
شركات إنتاج المحاصيل المختلفة وكذللك شركات الإلتات إنتاج الأسمدة و المبيدات و التقاوي والآلآت المختلفة.

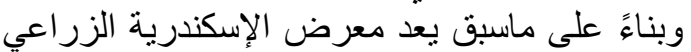

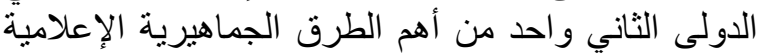

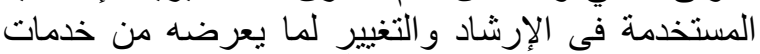

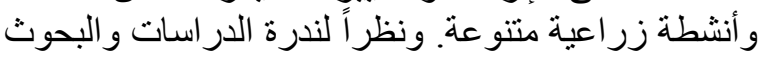


و التواصل Networking Opportunities، و وجمع المعلومات Information، والترفيه Leisure حيث تم التم قياس كل غرض من خلال مجموعة من السمات المحددة له. وقد تم تحقيق ذللك من خلال الهدف الثان الثانى للار اسنة

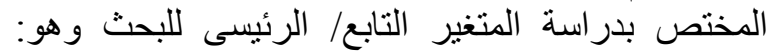

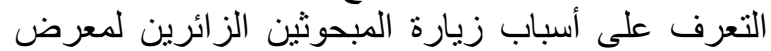

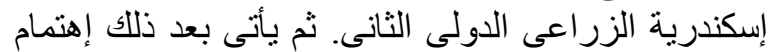

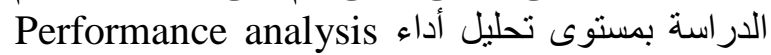
معرض إسكندرية الزر اعى الدولى أجرو أليكس الثانى من الثن

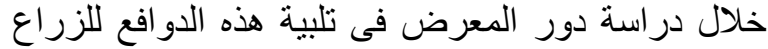

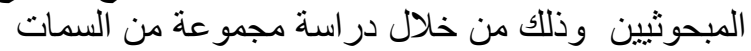
تتحصر تحت المؤشرات الأربعة السابق درن المات

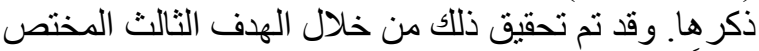

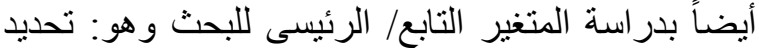

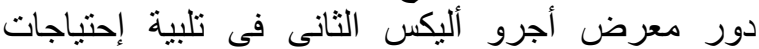

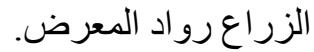

\section{3. الطريقة البحثية}

\section{3. المنهج المستخدم في هذه الدراسة هو منهج دراسة}

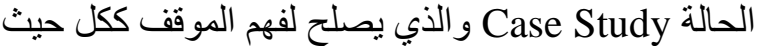

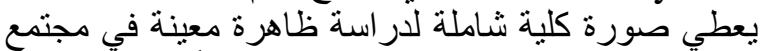
محدد. وقد تكون الحالة موضع البحث فردة فرداً واحدة أو أو أسرة

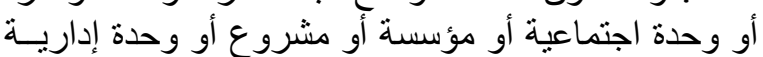

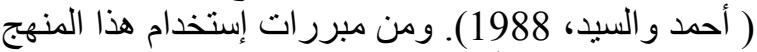

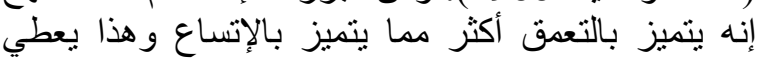

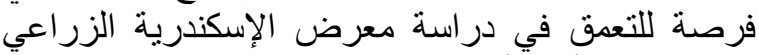

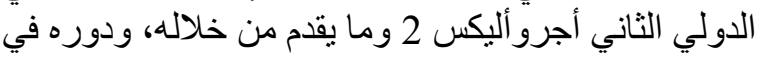

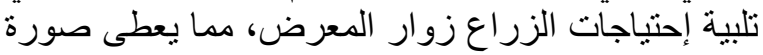
واضحة له .

2.3. التعاريف الإجرائية:

تتناول التعاريف الإجرائية توضيحاً للمفاهيم الرئيسية الواردة فى هذه الدر اسة و التي تشتمل على على مايلى

1.2.3. دوافع المبحوثين تجاه حضور معرض الإلئ الإكندرية

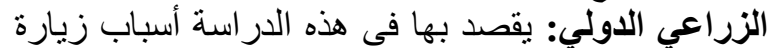

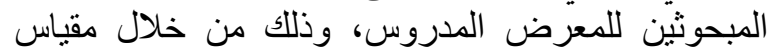

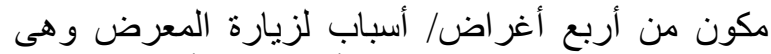

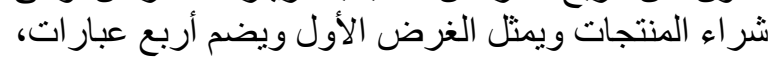

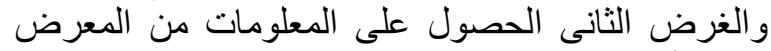

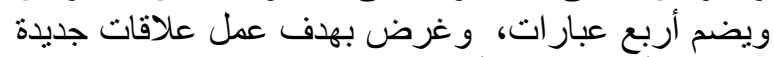

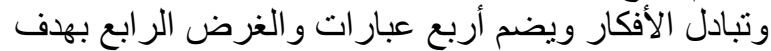

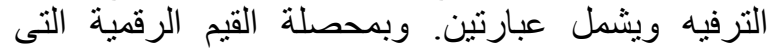

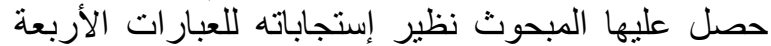

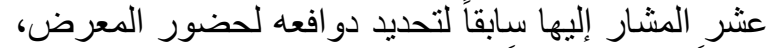

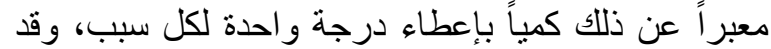

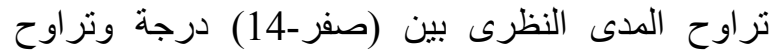
المدى الفعلى مابين (صفر - 14) درجة المئ أمكن تصنيف المبحوثين وفقاً لهذا المدى إلى ثلاثل فئات.
الإجتماعية حيث تتعلق هذه التوقعات بسلوك الثخص تجاه

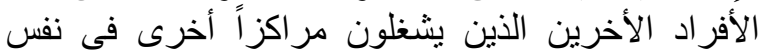

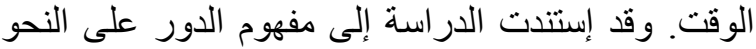

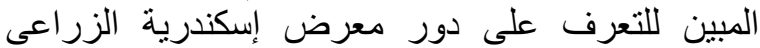

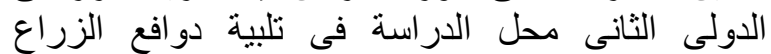
المبحوثيين لحصور المعرض.

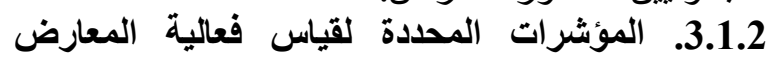
الإرشادية

تعتبر الفرضية الأساسية لأي معرض هو الجمع بين

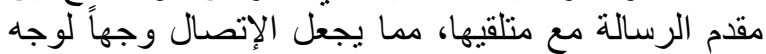

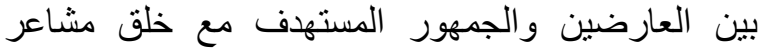

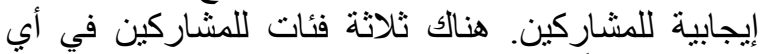

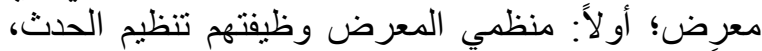

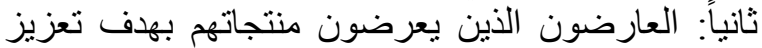

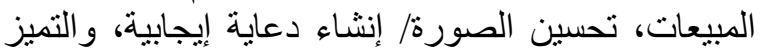

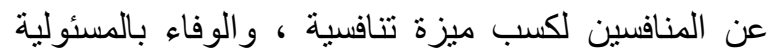

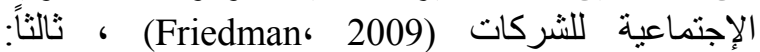

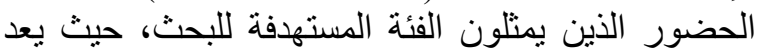

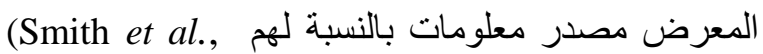
Information 2003) أحد المؤشرات لتحليل أداء (Performance Analysis)

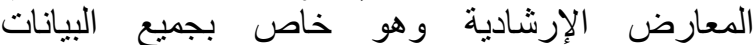

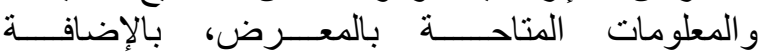
إلــى ثلاث مؤشرات أخرى: مؤشر شراء المنتجات المباء Products Purchase المنتجات المعروضة بالمعارض، ومؤشر فرص التواصل اصل rkingNetwo Opportunities الأفكار مع الأخرين ومقابلة الخبراء و القدرة على حضور الرير

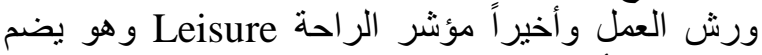
البر امج والأنشطة النرفيهية المتاحة بالمعارض .(Breiter and Milman, 2006; Whitfield and .Webber, 2011; Ivkov et al., 2015) وفى ضو ه هذه المؤشر ات؛ صنفت الدو افع فى عديد

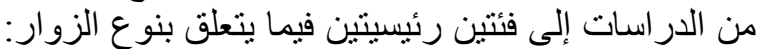

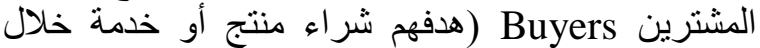

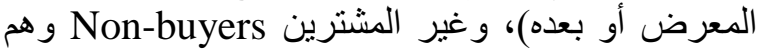

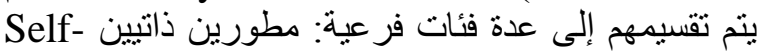
developers العارضة وحضور الندوات وورش العمل من أجل التعليم وتطويرحياتهم المهنية) (Education and Business) ، والمتصفحون browsers (هدفهم جمع المعلومات the عن كل ماهو جديد)، والجمهور العامع العام Information general public

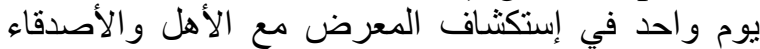

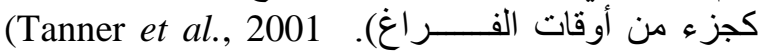
هزال هذا الإطار إهتمت الدراسة الحالية بدر اسة دو افع المبحوثين

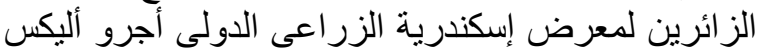

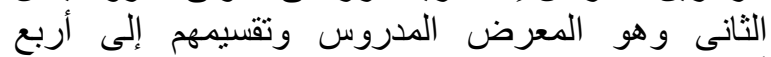
أغر اض: بهدف شر اءالمنتجات Products Purchase، 


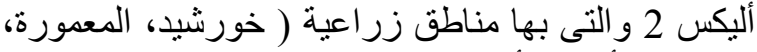

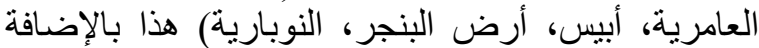

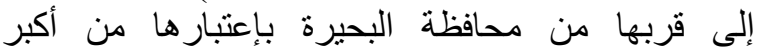

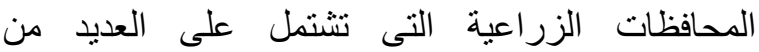

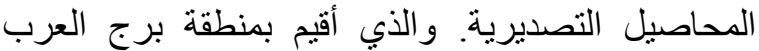

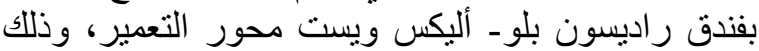

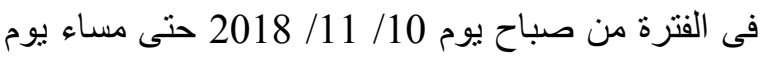

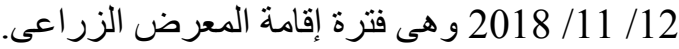
4.3. الثاملة والعينة للبحث فئرة

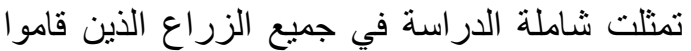
بزيارة معرض الإسكندرية الزراعي الدئ الدولي الثناني، حيث

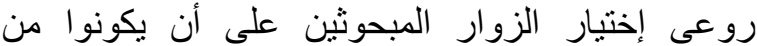

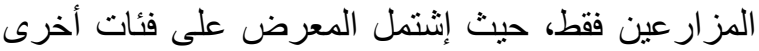

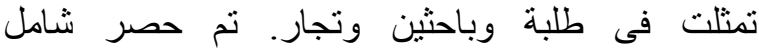

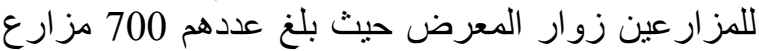
على مدار الثلاث أيام. وقد أمكن تجميع البيانات من عن عينة

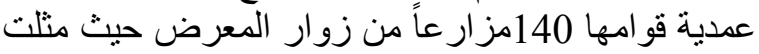
نسبة 20\% من مجموع المزارعين و هم الذين تم مقابلتهم الزمار خلال فترة إقامة المعرض الزئ الزراعى.

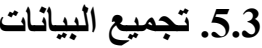

تم إستيفاء البيانات اللازمة لتحقيق أهداف هذا البحث

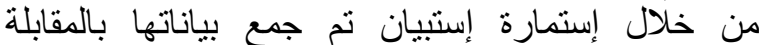

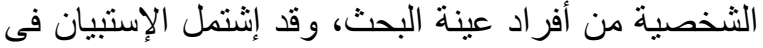

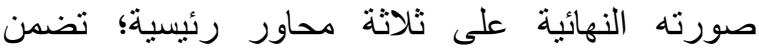

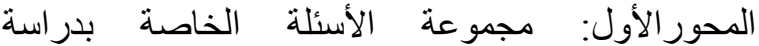

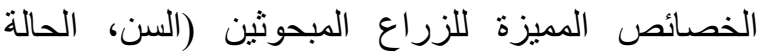

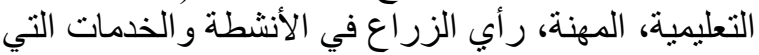

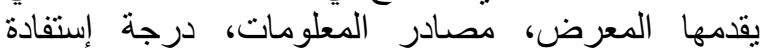
الزراع من حضور المعارض الزران الزية السابقة).

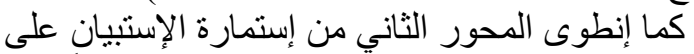
الأسئلة المتعلقة بالمتغير التنابع المتمثل في قياس كلاً من:

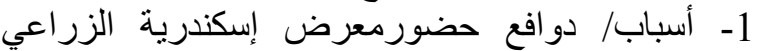

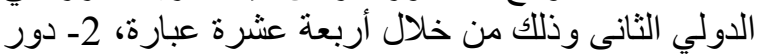

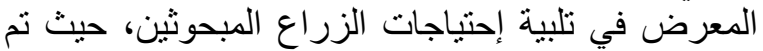

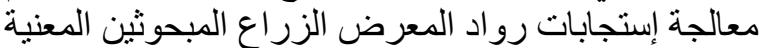

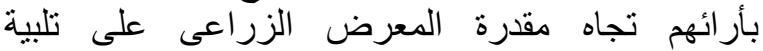

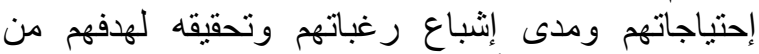

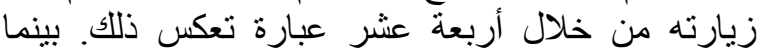

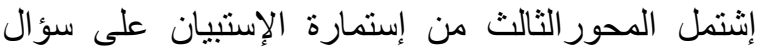

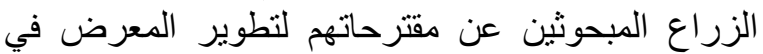

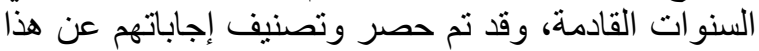

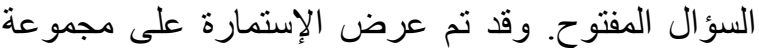

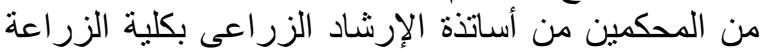

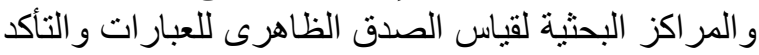

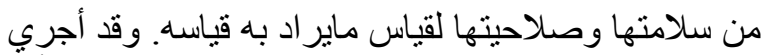

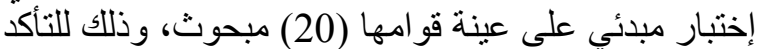
من مدى سلامة وصلاحية الأسئلة ومدى فهم المبحوثين مينين
2.2.3. دور المعرض فى تلبية إحتياجات المبحوثين:

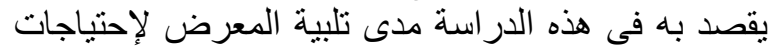

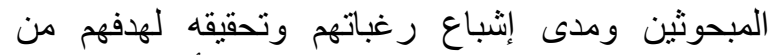

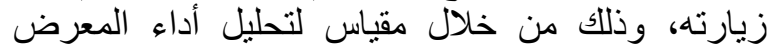

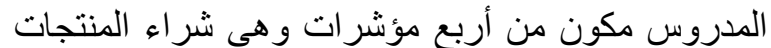

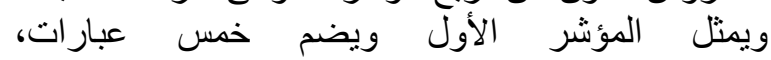

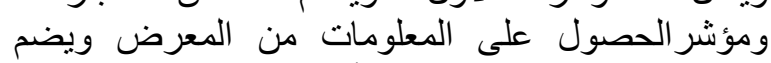

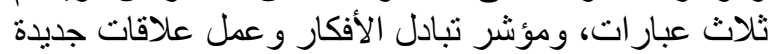

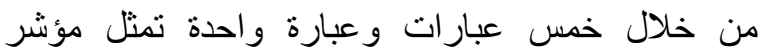

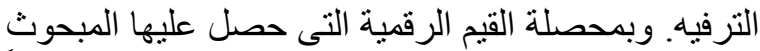
نظير إستجاباته للعبارات الأربعة عشر المشيه المشار إليها سابقاً

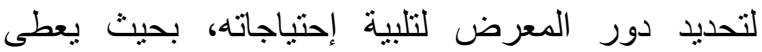
المبحوث درجتان في حالة تلبية المعرض لإلياته لإهنماماتها،

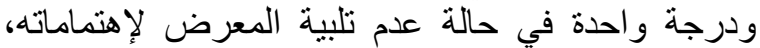
وبذلك نراوح المدى النظرى بين (14-28) درجة الئة ونراوح

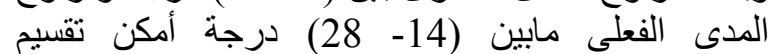
المبحوثين وفقاً لهذا المدى إلى ثلاث فئات.

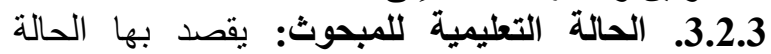

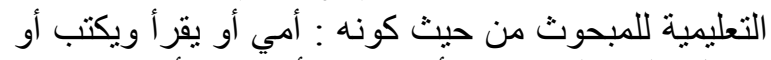

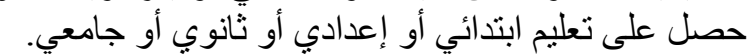

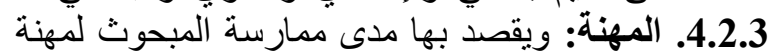

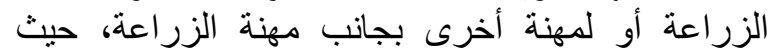
يعطى المبحوث الذي يمارس مهنة الزراعة الزئة فقط درجة

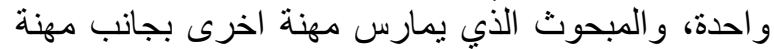

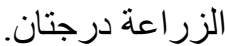
5.2.3 تعدد مصادر المعلومات: بقصد بها عدد المصادر

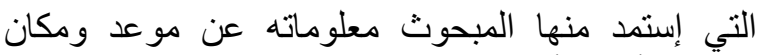
معرض أجرو أليكس الزراعي الثناني، حيث يعطى دربه درجة ودكان

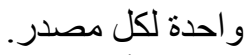

6.2.3. أراء الزراع في الأنثطة والخدمات التي يقدمها

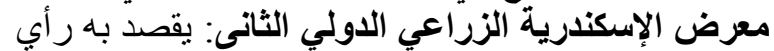

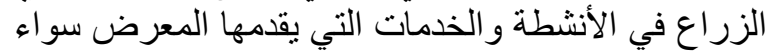

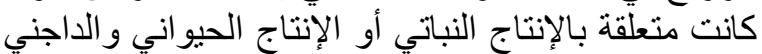

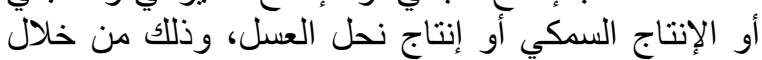

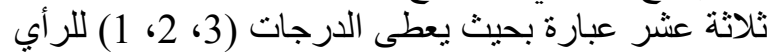

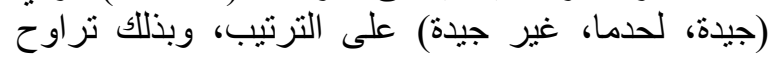
المدى النظرى لهذا المتغير بين (13-39) درجة، ولئ، ويشار إليه بمحصلة القيم الرقمية الدالة على أرائهم في الأنشطة درينة و الخدمات التي يقدمها المعرض.

7.2.3 درجة الإستفادة من حضور المعارض المرض الزراعية

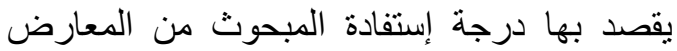

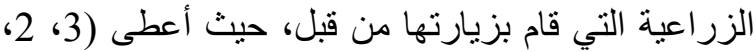

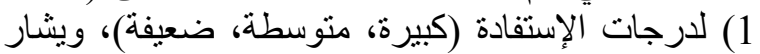

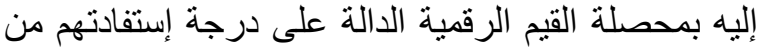
حضور المعارض الزر اليهة الزية السابقة. 3.3. منطقة البحث المث لقد تحدد المجال الجغر افي في محافظة الإسكندرية

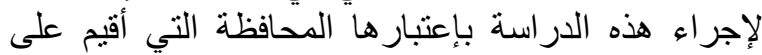
أرضها معرض الإسكندرية الزراعي الدولي الثناني أجرو الثيم 


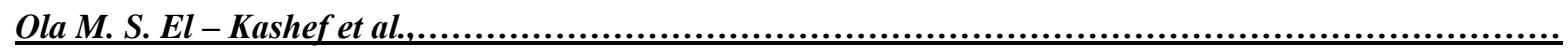

جدول (1): توزيع المبحوثيين وفقا للمتغيرات المستقلة المدروسة $(140=0)$

\begin{tabular}{|c|c|c|}
\hline & \multirow{3}{*}{ العدد } & \multirow{2}{*}{ المتغير } \\
\hline \multirow{2}{*}{$\begin{array}{c}\% \\
22,9\end{array}$} & & \\
\hline & & 1-السن صغار السن ( أقل من 40 سنة ) \\
\hline 45,7 & 64 & متوسطى السن ( 40- 58 سنة ) \\
\hline 31,4 & 44 & كبار السن (59 سنة فأكثر ) \\
\hline \multicolumn{2}{|c|}{50,28} & المتوسط الحسابى \\
\hline \multicolumn{2}{|c|}{13,56} & الإنحراف المعيارى \\
\hline 19,3 & 27 & 2- الحالة التعليمية \\
\hline 21.4 & 30 & يقر أويكتب \\
\hline 5,7 & 8 & تعليم إبتدائى \\
\hline 5 & 7 & تعليم إعدادى \\
\hline 25,7 & 36 & تعليم ثانوى/ دبلوم \\
\hline 22,9 & 32 & تعليم جامعى \\
\hline 50 & 70 & 3- المهنة \\
\hline 50 & 70 & عمل إضافى بجانب الزر اعة \\
\hline 62,1 & 87 & 4- تعدد مصادر المعلومات من 2 مصدر \\
\hline 30,7 & 43 & 2- 3 مصادر \\
\hline 7,2 & 10 & 4 مصادر فأكثر \\
\hline 17,8 & 25 & 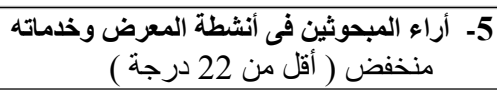 \\
\hline 55 & 77 & متوسط (22- 30 درجة \\
\hline 27,1 & 38 & مرتفع (31 درجة فأكثر) \\
\hline \multicolumn{2}{|c|}{26,89} & المتوسط الحسابى \\
\hline \multicolumn{2}{|c|}{5,48} & الإنحراف المعيارى \\
\hline 56 & 56 & 6- درجة الإستفة أقل من حضور المعارض الزراعية 6 درجة ) \\
\hline 41 & 41 & متوسطة ( 6 - 10 درجة ) \\
\hline 3 & 3 & مرتفعة ( 11 درجة فأكثر ) \\
\hline \multicolumn{2}{|c|}{5,15} & المتوسط الحسابى \\
\hline \multicolumn{2}{|c|}{2,79} & الإنحراف المعيارى \\
\hline
\end{tabular}

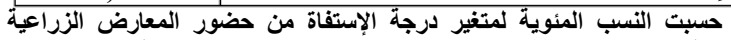

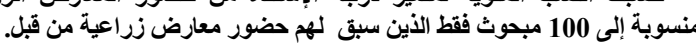

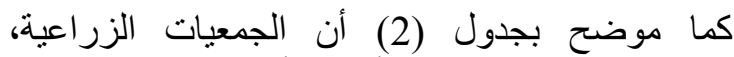

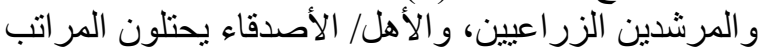
الثلاثة الأولى بنسب تكرار (61,4 \% \% 33,6 \% \%

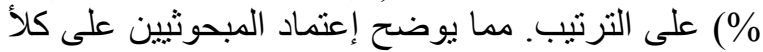

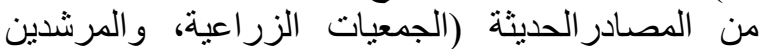

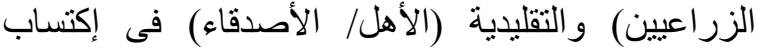

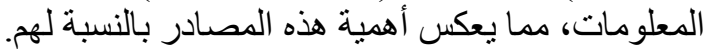

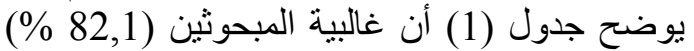
أرائهم في الأنشطة والخدمات التي يقدمها المعرض الئن محل

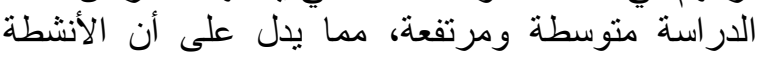

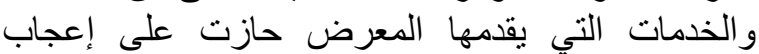
المبحوثين مما يمكنهم من زيادة الإستفادة والإستمتاع بما الإليا
6.3. تحليل البيانات البحثية

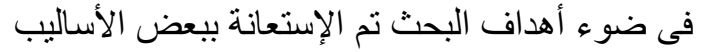

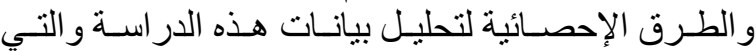

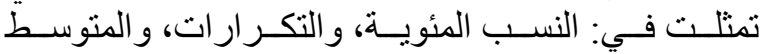

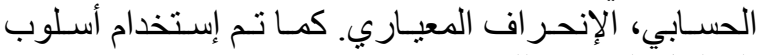

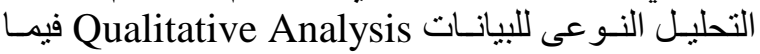

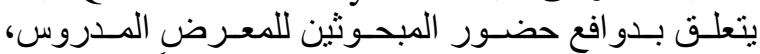

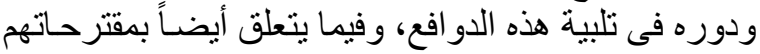

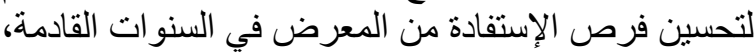

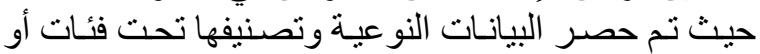

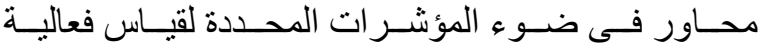

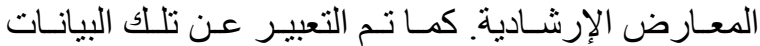

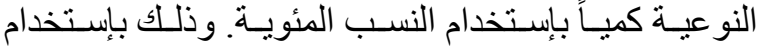

البرنامج الإحصائي للعلوم الإجنماعية (SPSS).

\section{4. - - النتائج والمناقثة}

1.4. الخصائص المميزة للمبحوثين

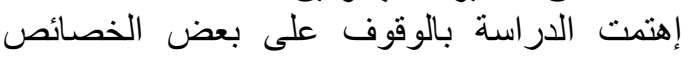

المميزة للمبحوثين كمتغير ات بحثية تفيد في توصيف التئ عينة

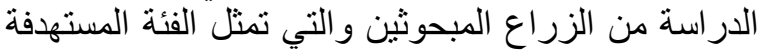

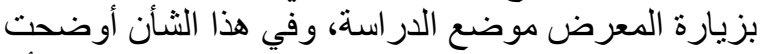

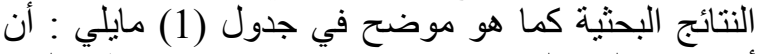

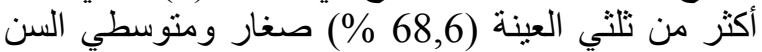

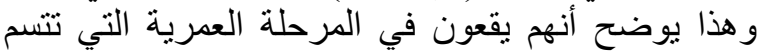

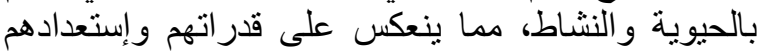

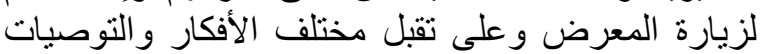

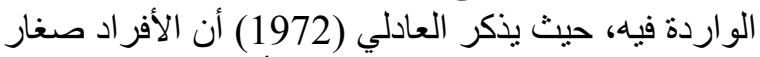

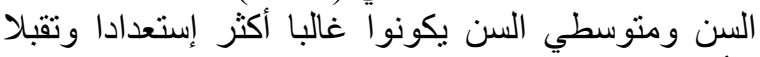

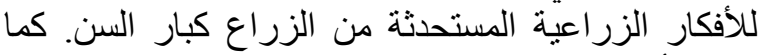

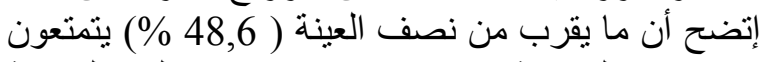

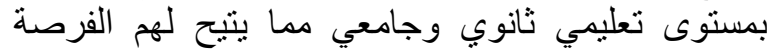

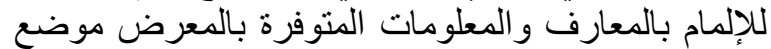

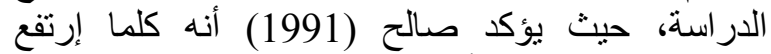

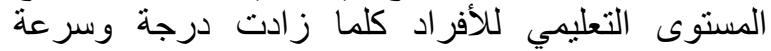

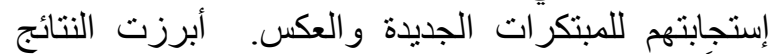

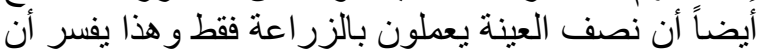

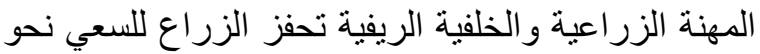

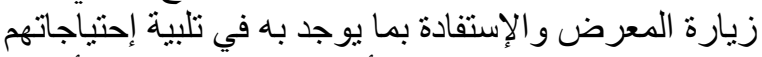

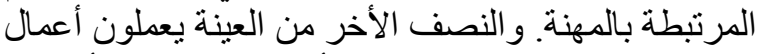

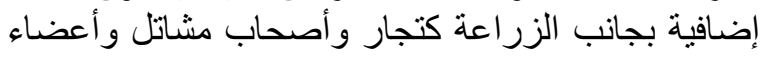

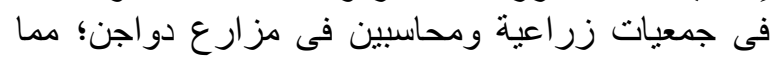
يعكس المستوى التعليمى العالى كما وضئ في في النتائج.

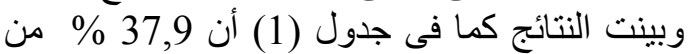

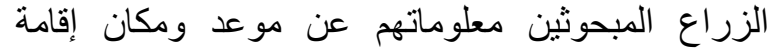

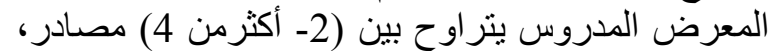

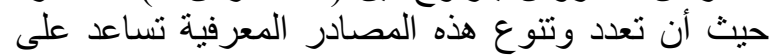

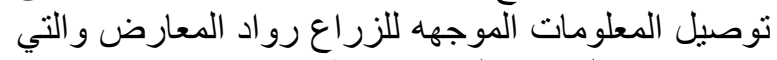

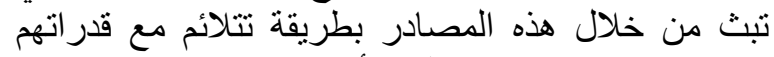

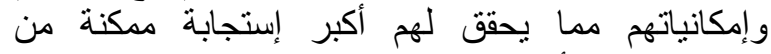
المعرض. كما أبرزت النتائج عن هذه المصادير المئه المعرفية 
وعن أكثر المعارض الزراعية التي زارها الزراع

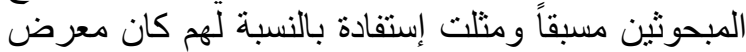

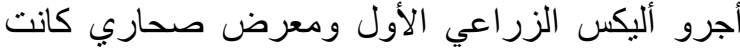

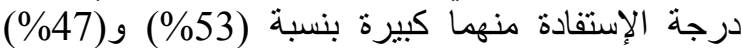
على الترتيب في حين إنخفضت الإستفادة الإنة الكبيرة في كل

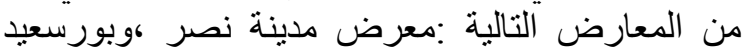

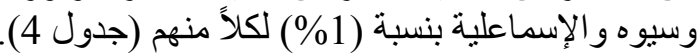

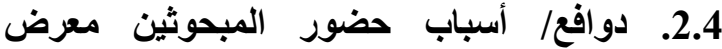
الإسكندرية الزراعي الدولي الثاني

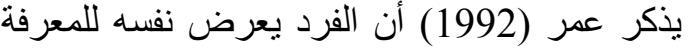

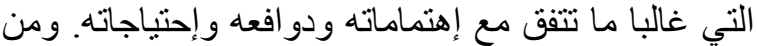

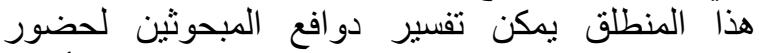

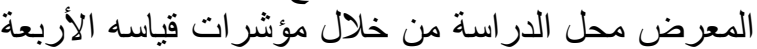

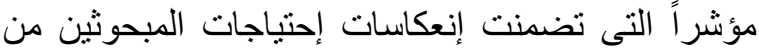

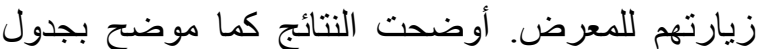

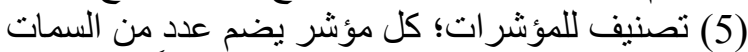
Attributes

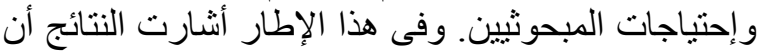

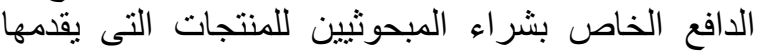

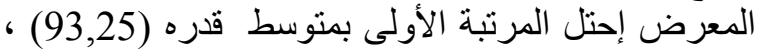

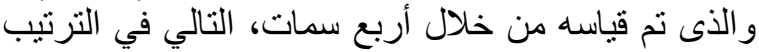

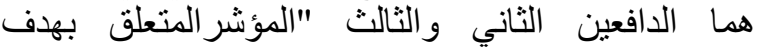

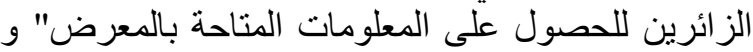

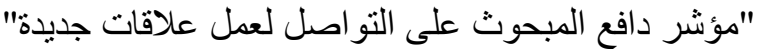

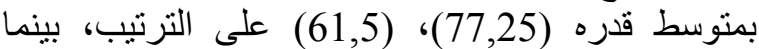

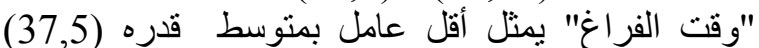

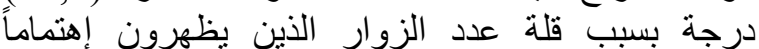
بالأنشطة الترفيهية.

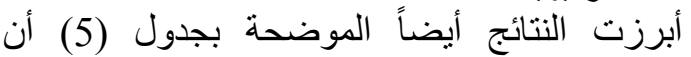

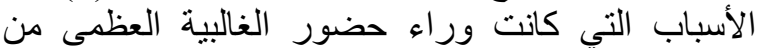

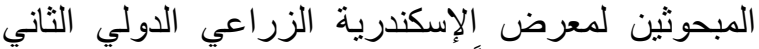

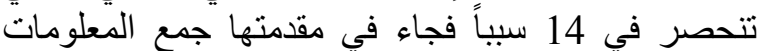
لشر اء المزيد من المنتجات، فحص المنتجات قبل فيل الثراء، الثطاء

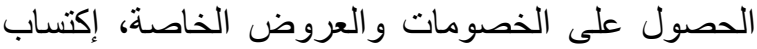

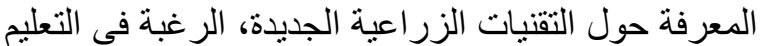

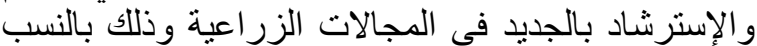

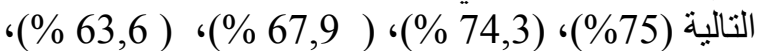
(2\% 61,4) المبحوثين رواد المعرض الزراعي المدروس (78,5 \% \%

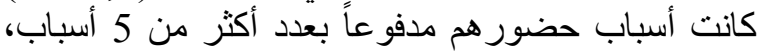

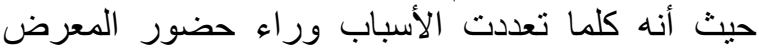

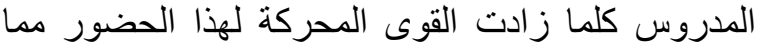

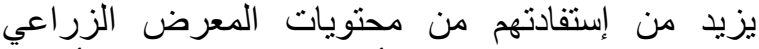
المدروس ( جدول 6). كما أن تحديد وفهم دو افع/ أسباب الزباعب

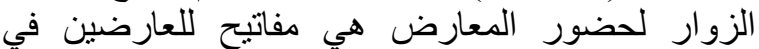
تحقيق أهدافهم من خلال تطوير إستر اتيجيات لتوليد ليد أفكار مناسبة لتكر ار الزيارة من قبل الحضور

(Godar and O`Connor, 2001; Ling- Yee, 2006)
جدول (2): التوزيع التكرارى للمصادر التى يستمد منها الزراع

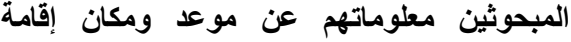

المعرض (ن = 140).

\begin{tabular}{|c|c|c|}
\hline$\%$ & التكرار & مصادر المعلومات \\
\hline 61,4 & 86 & الجمعية الزر اعية \\
\hline 33,6 & 47 & المرشدين الزر اعيين \\
\hline 32,9 & 46 & الأهل / الأصدقاء \\
\hline 13,6 & 19 & الإنترنت \\
\hline 12,9 & 18 & الإتصالات التليفونية \\
\hline 6,4 & 9 & نشرات فنية \\
\hline 5,7 & 8 & الملصقات إرشادية \\
\hline 5 & 7 & الصحف و المجلات \\
\hline 1,4 & 2 & الأبناء \\
\hline
\end{tabular}

يتضمنه المعرض من أنشطة وخدمات، حيث بيساعدهم

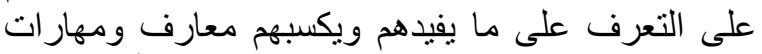
زراعية مفيدة سواء في الإنتاج النباتي أو الحيواني

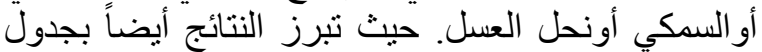

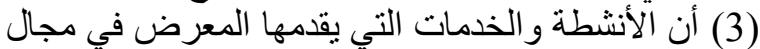
الإنتاج النباتي تصدرت الأنيطة المرتبة الأولى بمتوسط حسابي

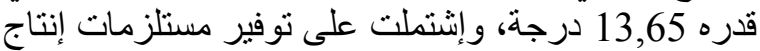
المحاصيل الحقلية من تقاوي وأسمدة ومبيدات، توفيلتيل توفير

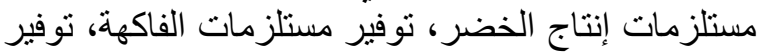

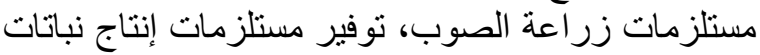

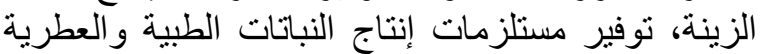

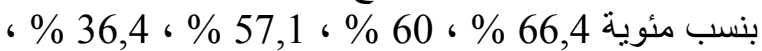

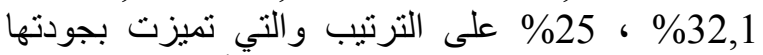
بدرجة جيدة. وإحتلت المرتبة الثانية للانثنطة والخئن الخدمات المتعلقة بالإنتاج الحيواني بمتوسط حسابي قدره

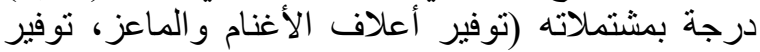

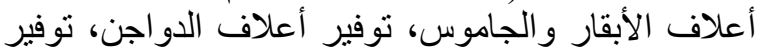

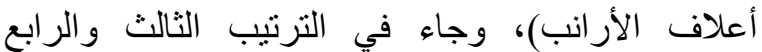

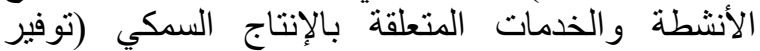

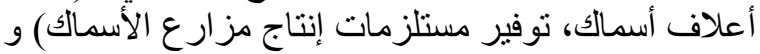

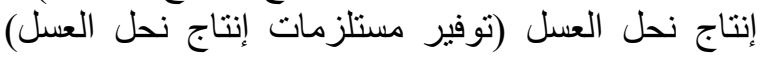
بمنوسط حسابي قدره (3,53) درجة (2,14) درجة على نلى الترتيب.

كما نشير النتائج أن (44 \% \%) من المبحوثين درجة إستفادتهم من حضور المعارض الزير الزراعية كانت متوسطة الزئة

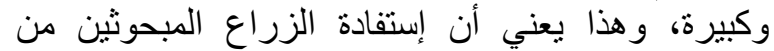

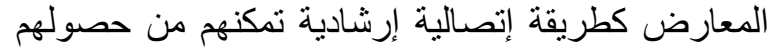

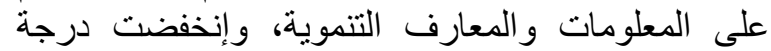
الإستفادة لاى (56\%) وتعزى هذه النقارف النتيجة للإمكانيات

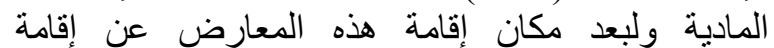

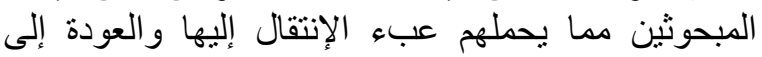
قر اهم التي يعيشون فيها كما هو موضح في جدول (1). 


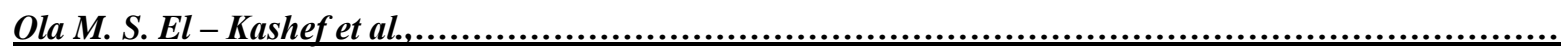

جدول (3) : توزيع المبحوثين وفقا لأرائهم عن الأنثطة والخدمات التى يقدمها معرض إسكندرية الزراعى الدولى الثانى (ن = 140)

\begin{tabular}{|c|c|c|c|c|c|c|}
\hline \multicolumn{2}{|c|}{ غير جيدة } & \multicolumn{2}{|c|}{ ل لحدما } & \multicolumn{2}{|c|}{ جيدة } & \multirow{2}{*}{ الأنشطة والخدمات } \\
\hline$\%$ & 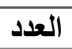 & $\%$ & 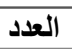 & $\%$ & 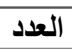 & \\
\hline 8,6 & 12 & 25 & 35 & 66,4 & 93 & 1أولا :مايتعلق بالإنتاج النباتي \\
\hline 10 & 14 & 30 & 42 & 60 & 84 & 2- توفير مستلزمات انتاج الخضر \\
\hline 7,9 & 11 & 35 & 49 & $\mathbf{5 7 , 1}$ & 80 & 3- توفير مستلزمات انتاج الفاكهة \\
\hline 24,3 & 34 & 39,3 & 55 & 36,4 & 51 & 4- توفير مستلزمات زر اعة الصوب \\
\hline 34,3 & 48 & 33,6 & 47 & 32,1 & 45 & 5- توفير مستلزمات انتاج نباتات الزينة \\
\hline 50 & 70 & 25 & 35 & 25 & 35 & 6- توفير مستلزمات انتاج النباتات الطبية و العطرية \\
\hline \multicolumn{6}{|c|}{13.65} & المتوسط الحسابى \\
\hline 47,1 & 66 & 21,4 & 30 & 31,4 & 44 & 7- ثانيا : ما بتعلق بالإنتاج الحيوانى الأغنام و الماعز \\
\hline $\mathbf{3 4 , 3}$ & 48 & 37,1 & 52 & 28,9 & 40 & 8- توفير أعلاف الأبقار و الجاموس \\
\hline 35 & 49 & 37,9 & 53 & 27,1 & 38 & 9- توفير أعلاف الدواجن \\
\hline 40 & 56 & 33,6 & 47 & 26,4 & 37 & 10- توفير أعلاف الأرانب \\
\hline \multicolumn{6}{|c|}{7,53} & المتوسط الحسابى \\
\hline 40,7 & 57 & 38,5 & 54 & $\mathbf{2 0 , 7}$ & 29 & 11 ثالثاً :ما يتعلق بالإنتاج السمكي \\
\hline 42,9 & 60 & 38,6 & 54 & 18,6 & 26 & 12- نوفير مستلزمات إنتاج مز ارع الأسماك \\
\hline \multicolumn{6}{|c|}{$\mathbf{3 , 5 3}$} & المتوسط الحسابى \\
\hline 27,8 & 39 & 30,7 & 43 & 42,1 & 59 & 13- توفير مستلز بـإت إنتاج نحل العسل \\
\hline \multicolumn{6}{|c|}{2,14} & المتوسط الحسابى \\
\hline
\end{tabular}

جدول (4): التوزيع التكرارى لارجة إستفادة الزراع المبحوثين من حضور المعارض الزراعية (ن = 100). درجة الإستتفادة

\begin{tabular}{|c|c|c|c|c|c|c|}
\hline \multicolumn{6}{|c|}{ درجة الإستفادة } & \multirow{3}{*}{ إسم المعرض } \\
\hline \multicolumn{2}{|c|}{ ضعيفة } & \multicolumn{2}{|c|}{ متوسطة } & \multicolumn{2}{|c|}{ كبيرة } & \\
\hline$\%$ & التكرار & $\%$ & التكرار & $\%$ & التكرار & \\
\hline 2 & 2 & 19 & 19 & 53 & 53 & أجرو أليكس الأول \\
\hline 2 & 2 & 15 & 15 & 47 & 47 & صحارى \\
\hline صفز & صفز & 10 & 10 & 12 & 12 & أجرينا \\
\hline صفز & صفر & 1 & 1 & 6 & 6 & أجرو بيزنس \\
\hline صفز & صفر & 1 & 1 & 3 & 3 & المنيا \\
\hline صفر & صفر & 1 & 1 & 2 & 2 & طنطا \\
\hline صفز & صفز & صفر & صفز & 1 & 1 & مدينة نصر \\
\hline صفز & صفر & 2 & 2 & 1 & 1 & بورسعيد \\
\hline صفز & صفز & صفر & صفز & 1 & 1 & سيوه \\
\hline صفز & صفز & 1 & 1 & 1 & 1 & الإسماعيلية \\
\hline
\end{tabular}


خلال خمس سمات حيث أستطاع غالبية المبحوثيين تلبية إحتياجاتهم فيما يتعلق بهذه السمات الأتية، وإحتل المرتبة المبات

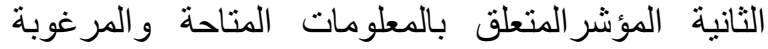

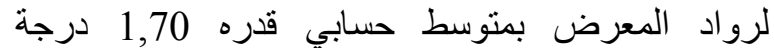
بمشتملاته، وجاء في الترتيب الثالثة و الر ابع مؤشرى قدرة

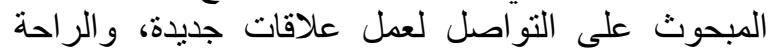

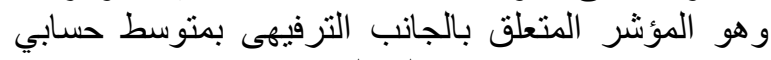
قدره 1,62، 1,47 درجة على التى الترنيب.

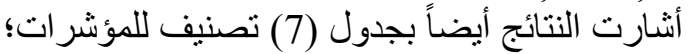

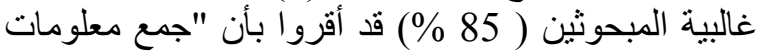

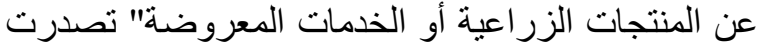

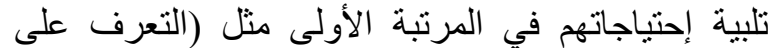

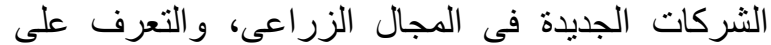

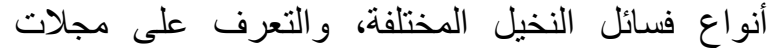

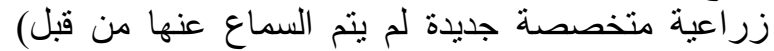

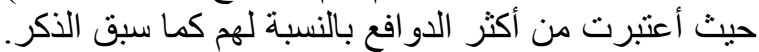

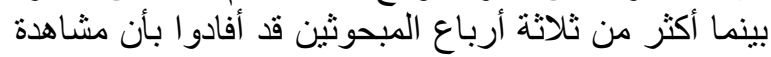

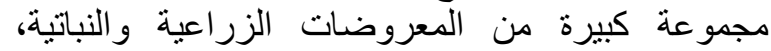

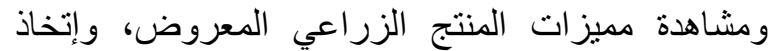

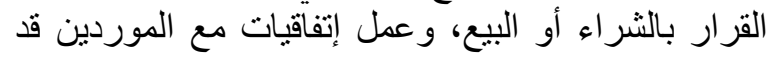

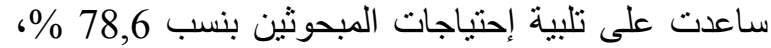

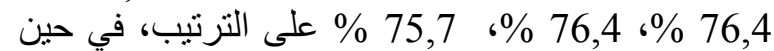
أفاد ثلاثة أرباع المبحوثين (75 \% \%) بأن زيارتهم للمعرض التئ

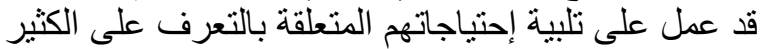

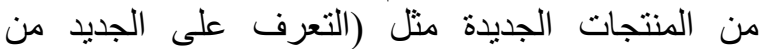
المبيدات الزراعية، و أصناف التقاوى الجديدة لبعض لجن لبن

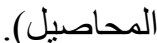
كما أوضحت النتائج أن ما يقرب من ثناثة أرباع

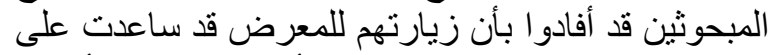
تلبية إحتياجاتهم المختصة بمقان بارنة أسعار المعار السوق وأسعار

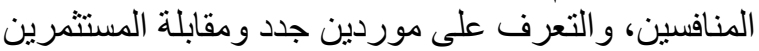
بنسب 73,6 \% \% 72 \% \% على على الترتيب. بينما أنشار أكثر

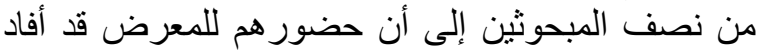
في تلبية إحتياجاتهم في: "حل مشكلاتهم مع المعن الموردين

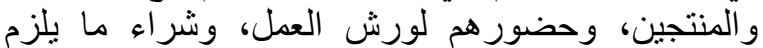

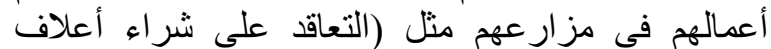

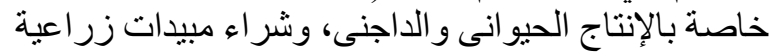

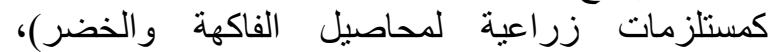

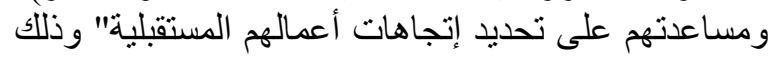

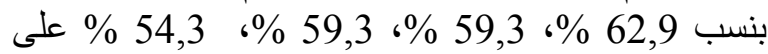
التوالي. كما أفادت النتائج أن ما يقرب من نصف بأن

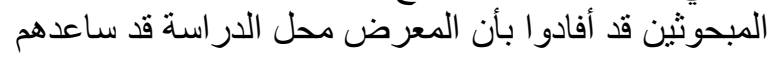

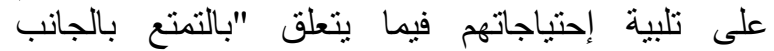

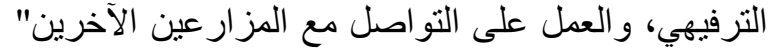
بنسب 47,9 \%، و 44,3 \% على على الترتيب .

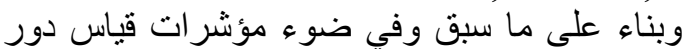

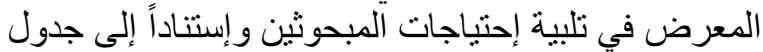

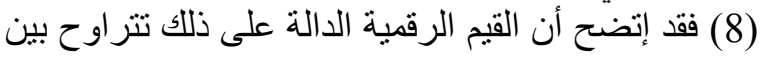

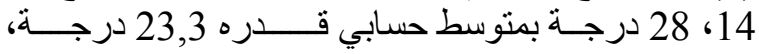

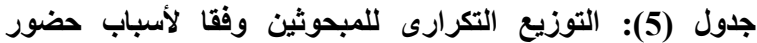
معرض إسكندرية الزراعى الدولي الثانى (ن = 140).

\begin{tabular}{|c|c|c|}
\hline$\%$ & 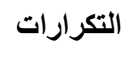 & أسباب زيارة المعرض \\
\hline \multicolumn{3}{|c|}{ شroducts Purchase شراء المنتجات } \\
\hline 75 & 105 & النميع المطلومات لشراء المزيد من \\
\hline $\mathbf{7 4 , 3}$ & 104 & فحص المنتجات قبل الثراء \\
\hline 67,9 & 95 & الترويجية الخاصة الخصومات والعروض \\
\hline 49,3 & 69 & الاجراءنى مستلزمات الإتتاج الحيواني/ \\
\hline 66,6 & 93,25 & المتوسط \\
\hline \multicolumn{3}{|c|}{ Information المعلومات } \\
\hline 63,6 & 89 & الجديدةب المعرفة حول التقتيات الزراعية \\
\hline 61,4 & 86 & 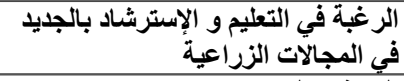 \\
\hline 49,3 & 69 & التَعرف على الإبتكارات \\
\hline 46,4 & 65 & الاخولة في مجالات الإستثمارات جليدة الحالية أو \\
\hline 55,2 & 77,25 & 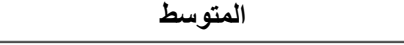 \\
\hline \multicolumn{3}{|c|}{ فرص التواصل Networking Opportunities } \\
\hline 50 & 70 & تبادل الأفكار مع الأخرين \\
\hline 43,6 & 61 & حضور الندوات وورش العمل \\
\hline 42,9 & 60 & العثور على شركاء تجاريين جدل \\
\hline 39,3 & 55 & مقابلة المتخصصين و الخبراء من \\
\hline 43,9 & 61,5 & المتوسط \\
\hline \multicolumn{3}{|c|}{ Leisure الترفيه } \\
\hline 27,9 & 39 & التمتع بالأنثطة الترفيهية \\
\hline 25,7 & 36 & للحصول على جوائز قيمة \\
\hline 26,8 & 7,5 & نط \\
\hline
\end{tabular}

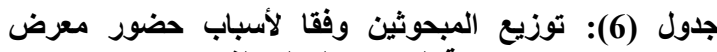

\begin{tabular}{|c|c|c|}
\hline$\%$ & 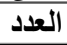 & أسباب حضور المعرض \\
\hline 21,4 & 30 & أقلّ من 5 أسباب \\
\hline 42,8 & 60 & 5- 8 أسباب \\
\hline 35,7 & 50 & 9 أسباب فأكثر \\
\hline \multicolumn{2}{|c|}{7,26} & المتوسط الحسابى \\
\hline \multicolumn{2}{|c|}{3,49} & الإنحراف \\
\hline
\end{tabular}

3.4. دور معرض الإسكندرية الزراعي الدولي الثاني في تلبية إحتياجات المبحوثين

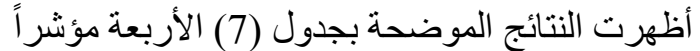

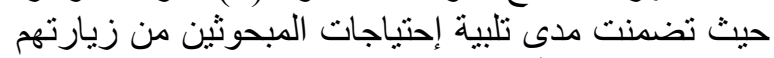

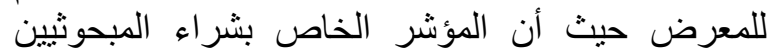

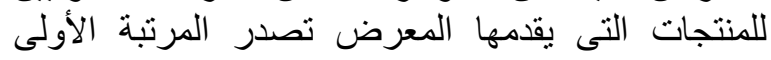

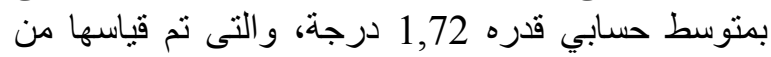




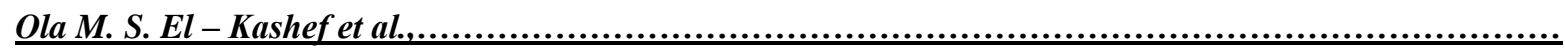

\begin{tabular}{|c|c|c|c|c|}
\hline \multicolumn{2}{|c|}{ ע } & \multicolumn{2}{|c|}{ نعم } & \multirow{2}{*}{ 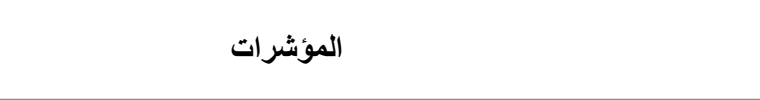 } \\
\hline$\%$ & العدد & $\%$ & العدد & \\
\hline \multicolumn{5}{|c|}{ شراء المنتجات Products Purchase } \\
\hline 21,4 & 30 & 78,6 & 110 & 1- مشاهدة مجموعة كبيرة من المعروضات الزراعية والنباتية \\
\hline 23,6 & 33 & 76,4 & 107 & 2- مشاهدة مميزات المنتج الزراعى المعروض أو الذذمة المعروضة \\
\hline 23,6 & 33 & 76,4 & 107 & 3- 3- إتخاذ القراربالثراء و البيع \\
\hline 25 & 35 & 75 & 105 & 4- التعرف على الكثير من المنتجات الجديدة \\
\hline 40,7 & 57 & 59,3 & 83 & 5- شراء مايلزم العمل فى المزارع \\
\hline \multicolumn{4}{|c|}{1,72} & المتوسط الحسابى \\
\hline \multicolumn{5}{|c|}{ المعلومات Information } \\
\hline 1 & 21 & 85 & 119 & 6- جمع معلومات عن المنتجات الزراعية أو الذدمات المعروضة \\
\hline 26,4 & 37 & 73,6 & 103 & 7- مقارنة أسعار السوق و أسعارالمنافسين \\
\hline 45,7 & 64 & 54,3 & 76 & 8- المساعدة على تحديد إتجاهات أعمالهم المستقبلية \\
\hline \multicolumn{4}{|c|}{1,70} & 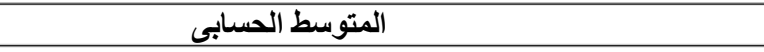 \\
\hline \multicolumn{5}{|c|}{ فرص التواصل Networking Opportunities } \\
\hline 24,3 & 34 & 75,7 & 106 & 9- عمل إتفاقيات مع الموردين \\
\hline 27,9 & 39 & 72,1 & 101 & 10- التعرف على موردين جدل ومقابلة المستثمرين \\
\hline 37,1 & 52 & 62,9 & $\mathbf{8 8}$ & 11- حل المشكلات مع الموردين والمنتجين \\
\hline 40,7 & 57 & 59,3 & 83 & 12- حضور ورش العمل \\
\hline 55,7 & 78 & 44,3 & 62 & 13- العمل على التواصل مع المزارعين الأخرين \\
\hline \multicolumn{4}{|c|}{1,62} & المتوسط الحسابي \\
\hline \multicolumn{5}{|c|}{ Leisure الراحة } \\
\hline 52,1 & 73 & 47,9 & 67 & 14- التمتع بالجاتب الترفيهىى \\
\hline \multicolumn{4}{|c|}{1,47} & المتوسط الحسابى \\
\hline
\end{tabular}

جدول (8): توزيع المبحوثين وفقا لمدى تلبية المعرض

\begin{tabular}{|c|c|c|}
\hline$\%$ & العدد & الفئات \\
\hline 7,2 & 10 & منخفضة (أقل من 19 درجة ) \\
\hline 35,7 & 50 & متوسطة (19- 23 درجة ) \\
\hline 57,1 & 80 & مرتفعة (24 درجة فأكثر ) \\
\hline \multicolumn{2}{|c|}{23,33} & المتوسط الحسابى \\
\hline \multicolumn{2}{|c|}{3,31} & الإنحراف المعيارى \\
\hline
\end{tabular}

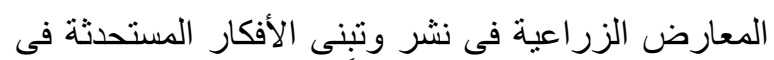

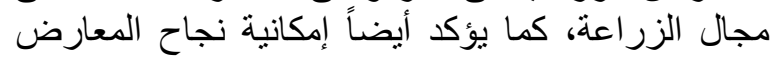
الزر اعية فى الظروف الزعة كئلة المصرية.
و إنحر اف معياري قدره 3,31 درجة، حيث إستطاع إلزي

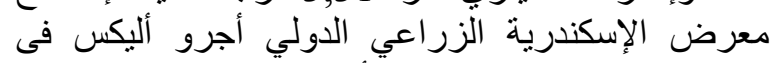

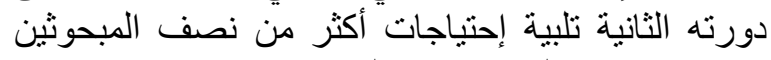

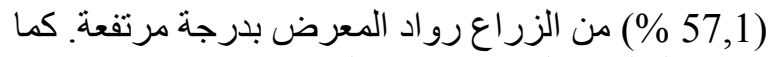

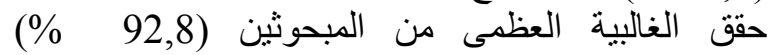

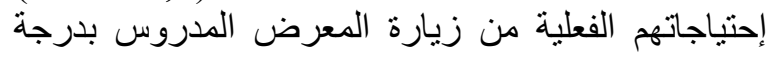

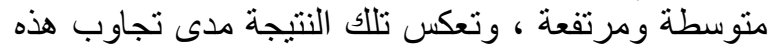

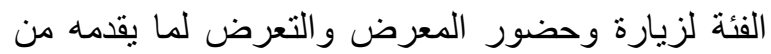
معلومات ومعارف ومدى إدر اكهم للعو ائد الإيجابية التي لئي

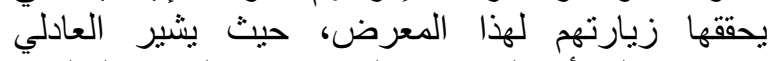
(1972) إلى أن الفرد من الناحية الإيكولوجية التعليمية

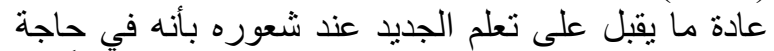

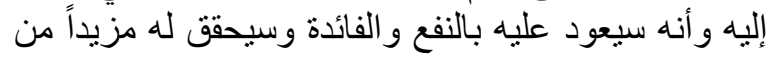
الإشباع و الرضا. تؤكد هذه النتيجة نتائج الثناوى (1995)

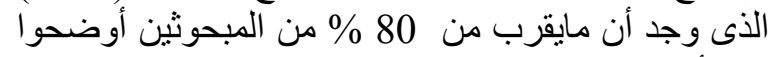

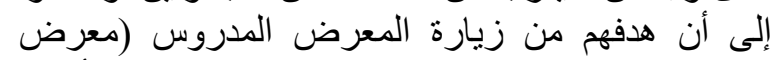
صحارى 1995) قد تحقق. وهذا ليؤكد على أهمية 


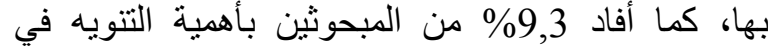

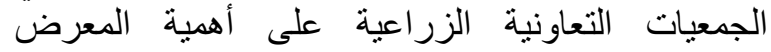

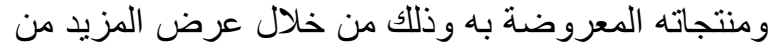

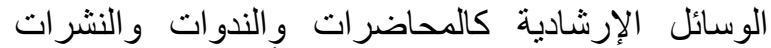
الإرشادية. و وأظهرت النتائج أيضاً ثلاث مقاث مقترحات

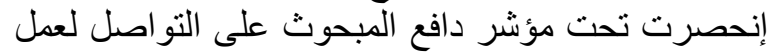
علاقات جديدة (جدول 9).
4.4. مقترحات المبحوثين لتطوير معرض الإسكندرية الزراعي الدولي الثاني المدروس التطوير دعرئ

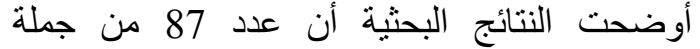

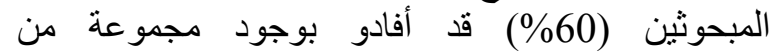

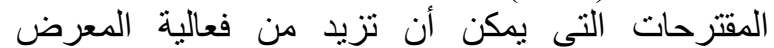

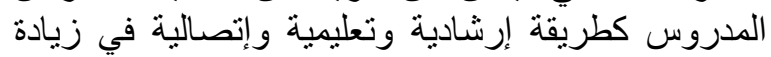
معلوماتهم ومعارفهم في المجالات الزراعية وائة المختلفة في

\begin{tabular}{|c|c|c|}
\hline$\%$ & 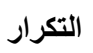 & المقترحات \\
\hline \multicolumn{3}{|c|}{ شroducts Purchase شراء المنتجات } \\
\hline 33,6 & 47 & 1- ضرورة الإهتمام بالإنتاج الحيو انى و الداجنى \\
\hline 26,4 & 37 & 2- الإهتمام بعرض الأنو اع الجديدة من السلالات المعدة للتصدير \\
\hline 26,4 & 37 & 3- الإهتمام بالإنتاج السمكى ومستلزمات مز ارع الأسماك \\
\hline 25,7 & 36 & 4- التوسع فى المعروضات لتغطى كافة الأنشطة \\
\hline 21,4 & 30 & 5- عمل منافذ لبيع المنتجات فى القرى وبأسعار مخفضة \\
\hline 17,9 & 25 & 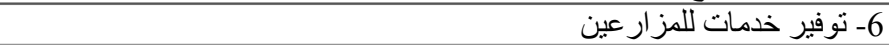 \\
\hline 13,6 & 19 & 7- عرض المعدات المناسبة لظروفنا المحلية \\
\hline $\mathbf{1 0 , 7}$ & 15 & 8- الإهتمام بعرض الأدوية البيطرية \\
\hline 7,9 & 11 & 9- عرض الثركات للمنتجات بالإسم المتداول بين الزارع \\
\hline 7,1 & 10 & 10 - 10 توفير منتجات خاصة بالثر كات الغذائية \\
\hline \multicolumn{3}{|r|}{ المعلومات Information } \\
\hline 22,1 & 31 & 11- الإهتمام بالإعلان عن مو اعبد المعارض و إماكن إقامتها مسبقاً \\
\hline 14,3 & 20 & 12 1 وجود شاشات داخل المعرض \\
\hline 9,3 & 13 & والمنتجات به في الجمعيات التعاونية الزر اعية بالمناطق الريفية عن أهمية المعرض \\
\hline \multicolumn{3}{|c|}{ فرص التواصل Networking Opportunities } \\
\hline 14,3 & 20 & 14- حل مشكلات الزراع الز ائرين \\
\hline $\mathbf{1 0 , 7}$ & 15 & 15- إلتزام الثركات المعلنة بالإتفاقيات المبرمة داخل المعرض \\
\hline 21,4 & 30 & 16- ضرورة التنسيق بين الثركات و الجمعيات الزر اعية \\
\hline
\end{tabular}

الخاتمة والتوصيات بعتبر معرض الإسكندرية الزراعي الدولي أجرو

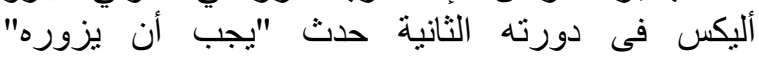

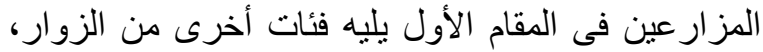

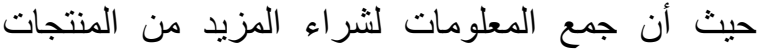
وفحص هذه المنتجات أعتبرت أكثر دافعين لزئن الفيارة

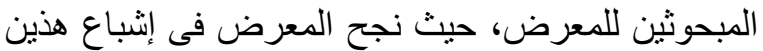

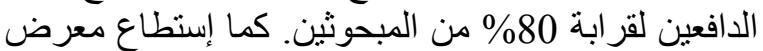

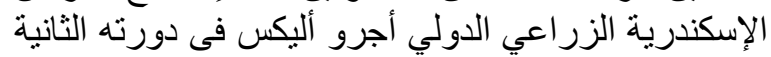

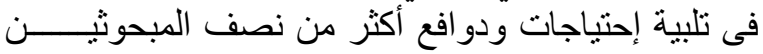

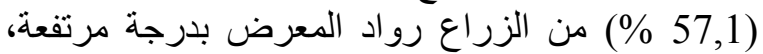

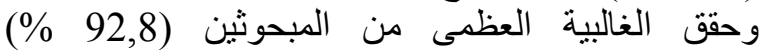
إحتياجاتهم الفعلية من زيارة المعرض المنة المدروس بدرجة

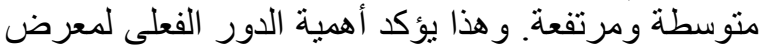

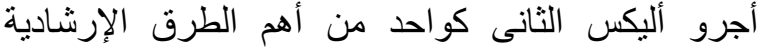

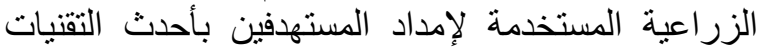

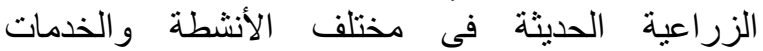
المعروضة. وبالر غم من هذا فماز ال معرض الزية الإسكندرية

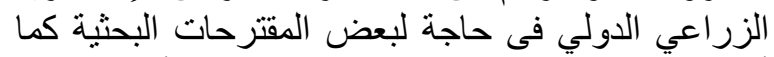

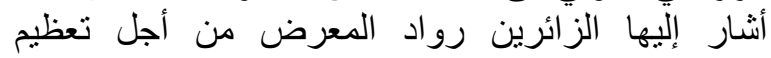
الإستفادة منه وتطويره فى السنواتئ رات المعرض القادمة. وفى إطار

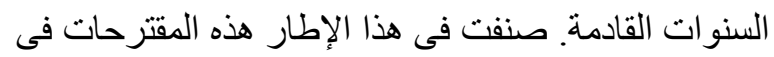

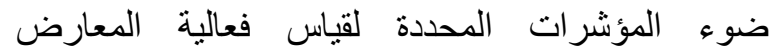

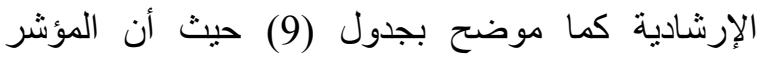

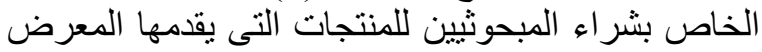

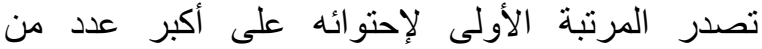
المقترحات وكانت أهمها كالأتى: أكثر من ثلثي الأني المبحوثين

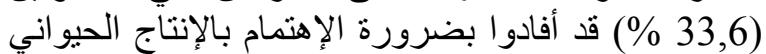
و الداجني وتوفير كافة مستلزماتهم. اعرب أكثر من ربع المبترمباتهوثين عن أهمية الإهتمام

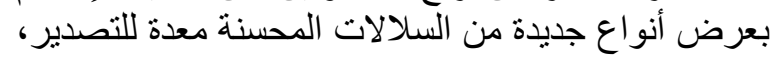

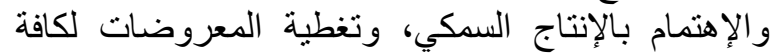
الأنشطة الزر اعية بنسب 26,4 \%؛ 26,4 \% \% \% 25,7 \% بينما أوضح المؤشر المتعلق بهدف الز ائرين للحصول

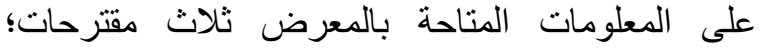

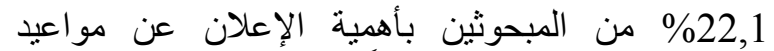

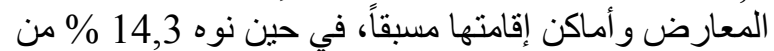

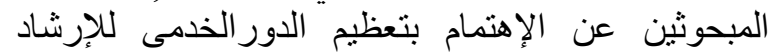

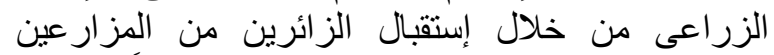

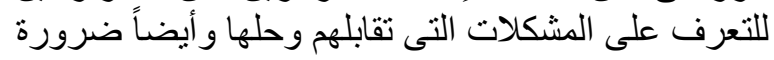

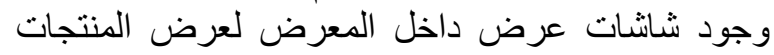


أحمد، غريب محمد السيد، السيد عبد العاطى السيد (1988). علم الإجتماع الريفى والحضرى، دارئ دار

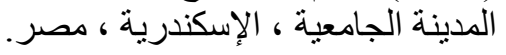

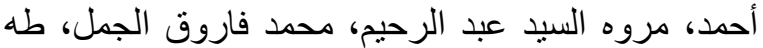

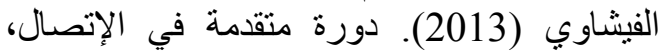
معهد بحوث الإرشاد الزراعي والتنمية الريفية،

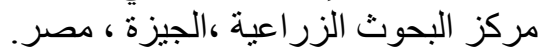

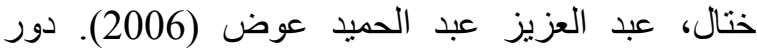
الإرشاد الزر اعى فى مجال حماية البيئة وصيانتها من التلوث بين زراع ومرشدى شعبة الإل الجبل الأخضر بالجماهيرية العربية الليبية، رئية رسالة

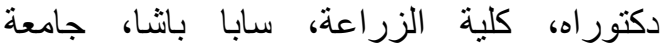
الإسكندرية.

الديب، أحمد دياب عيد، مرفت صدقية عبد عبد الوهاب، محمد مدوح يعقوب (2014). دور المعارض الزئ الزراعية في نشر التوصيات الفنبة لمنتجي نباتات الزينة في الزي التيه بعض قرى محافظة القليو بية، مجلة الجمعية العلمية للإرشاد الزراعي، مركز البحوث الزئ الزراعية، وزارة الزر اعة وإستصلاح الأر اضي، المجلد الزئد 18،

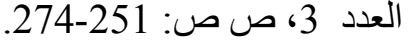

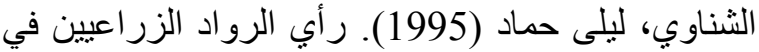

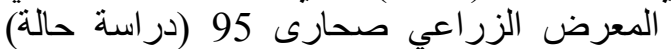

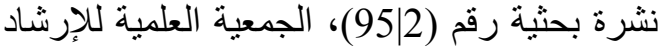

الزراعي، كلية الزراعة، جامعة الزية القاهرة، الجيزة الجية.

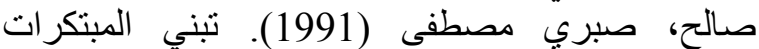
والأساليب الزراعية في الإرشاد الزراعي- قاعم الزئي

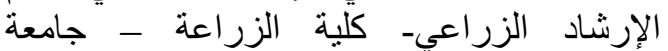
الإسكندرية ، مصر. - الزماد.

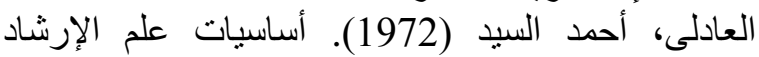
الزراعى، دار المطبوعات الجديدة، الإسكندرية، الإنة

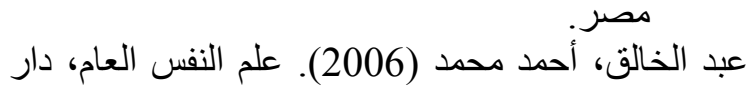
المعرفة الجامعية، الإسكندرية ، مصر.

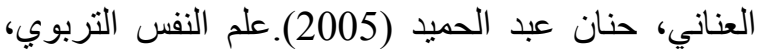

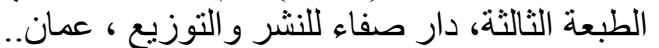

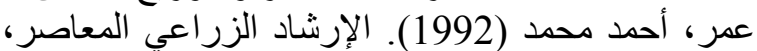
مصر للخدمات العلمية، القاهرة . الإنداد الزربة

مديرية الزراعة بالإسكندرية (2018).وزارة الزارة الزراعة

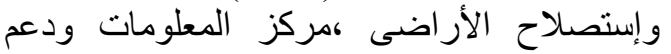
on lin Available at إنخاذ القرار.

http://agri-db.org/section/24.

\section{REFERENCES}

Borghini S., Golfetto F., Rinallo D. (2006). Ongoing industrial buyers, J. Bus. Res., 59: 1151-1159.

Breiter D. and Milman A. (2006). Attendees“ needs and service priorities in A Large convention center: Application of the importance-performance theory. Tourism Manage. 27: 1364-1370.
النتائج التى أسفر البحث عنها، وفى ضو و مقتضيات تحقيق الأهداف البحثية يمكن بلورة مجمو عة من التوصيات فلى على التي

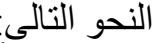
إستناداً إلى نتيجة الدر اسة وحقيقة أن الدافعين الأكثر

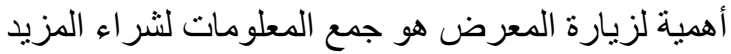

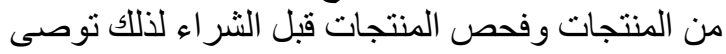

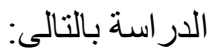

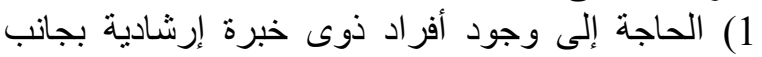

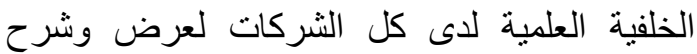

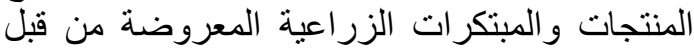

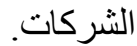

2) توفير عينات مجانية من منتجات الثركات المعروضة

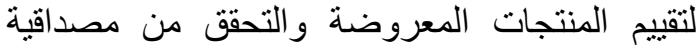
كفاءتها وفاعليتها قبل الإستخدام.

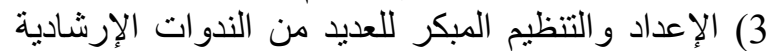

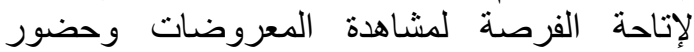

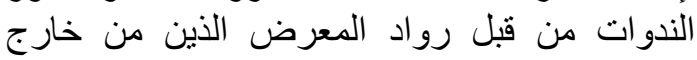
محافظة الإسكندرية.

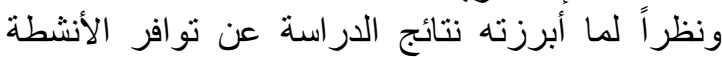

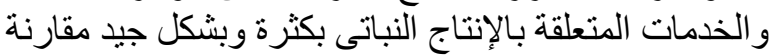

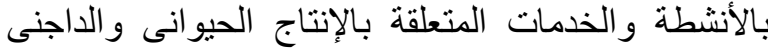

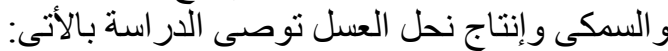
4) ضرورة التركيز على توفير كافة المستلزمات الإلتئ الإنتاجية

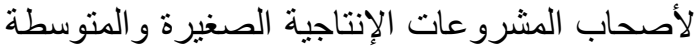

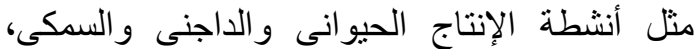
و إنتاج نحل العسل، و إنتاج عيش الغراج الغناب. 5)عرض منتجات تناسب صغار المربين وليس للإنتاج التجارى فقط.

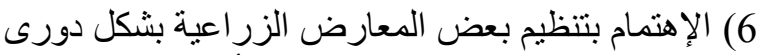

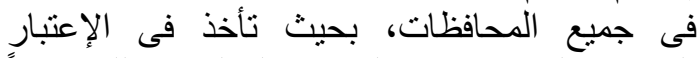
الدروس المستفادة من الدراسة الحالية، وذلك تفعيلاً

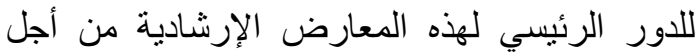

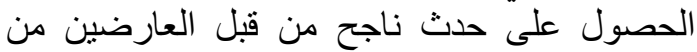
خلال إستخدامها كأداة تسويق نقاية من وفئ وفعالة للترويج

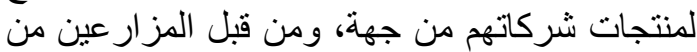

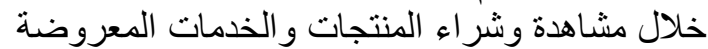

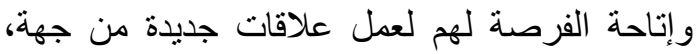

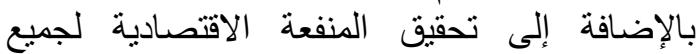
المؤسسات والهيئات المعنية بالمعارض الزفالفئ الزراعية من

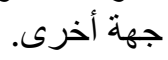

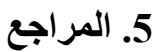

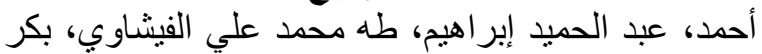

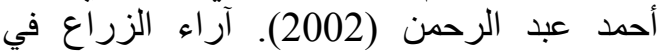
المعارض الزراعية كطريقة تعليمية إرشادية الزية

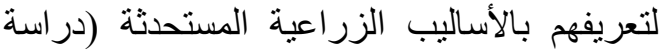

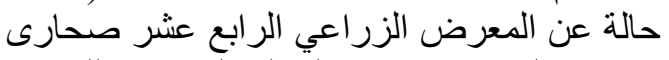

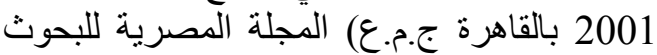

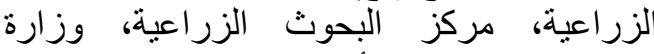
الزراعة وإستصلاح الأر اضي لمجلد 80، عدد3، الزرة 
Friedman S. (2009). Sponsorship: A Key to Powerful Marketing, Retrieved April 17, 2009 from

http://www.newjournalarticles.org/Sponsors hip_A_Key_to_Powerful_Marketing, 11257

Godar S.H. and O`Connor P.J. (2001). Same time next year - buyer trade show motives. Indust. Market. Manage, 30: 77-86.

Ivkov M., Blešić I, Raljić J.P., Džigurski A.I., Pivac T. and, Jovanović T. (2015). Visitors' Motives for Attending A Hybrid Event: A Case Study of Agricultural Fair. Economics of Agriculture, 61(1): 43:63.

Ling-Yee L. (2006). Relationship learning at trade shows: Its Antecedents and Consequences. Indust. Market Manage. $35(2), 166-177$.
Merton R. K. (1957). The role set, problems in Sociological theory, British J. sociology, 8 (2): 106-120.

Smith T. M., Hama K, and Smith P. M. (2003). The effect of successful trade show attendance on future show interest: exploring japanese attendee perspectives of domestic and offshore international events. J. Bus. and Indust. Market., 18(4/5): 403-418.

Tanner J. F., Chonko L. B. and Ponzurick T. V. (2001). A learning model of trade exhibition attendance, J. Convention Exhib. Manage., 3(3): 3-26.

Whitfield. J. and Webber D. J. (2011). Which exhibition attributes create repeat visitation? Int 1 J. Hospitality Manage., 30 (2): 439447. 